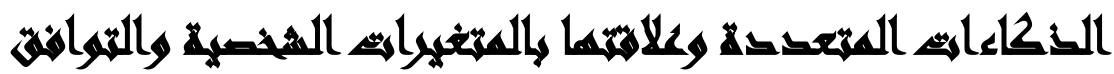

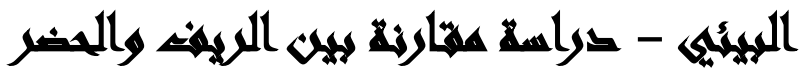

[ᄉ]

$$
\begin{aligned}
& \text { رزق سند إبراهيم(')- صفوت عبد الحميد صفوت(ץ)-- مني حسين الدهان(ץ) }
\end{aligned}
$$

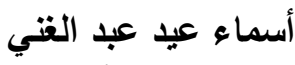

( ) كلية الآداب، جامعة عين شمس r) كلية الآداب، جامعة قناة السويس ب) كلية التربية

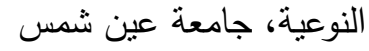

\section{المستخلس}

هدفت الدراسة إلي الكثف عن العلاقة بين الذكاءات المتعددة وعلاقتها بالمتغيرات الثخصية

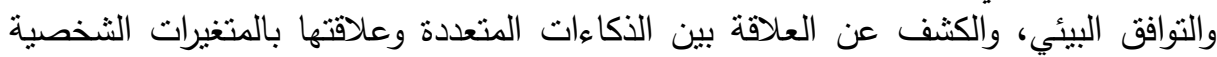

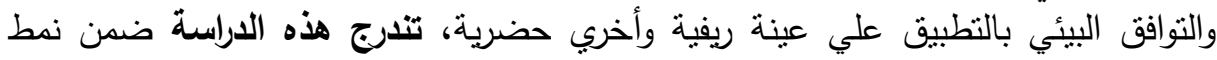

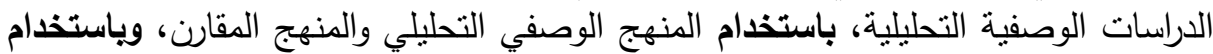

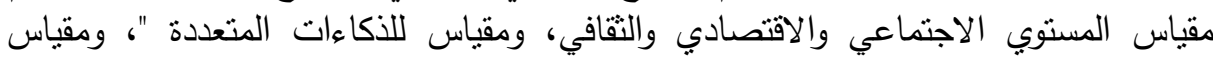

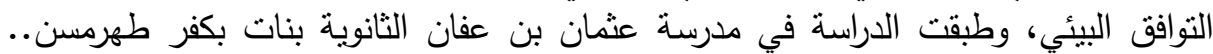

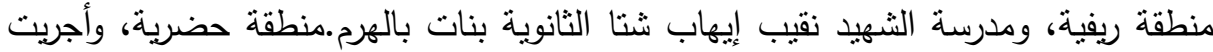

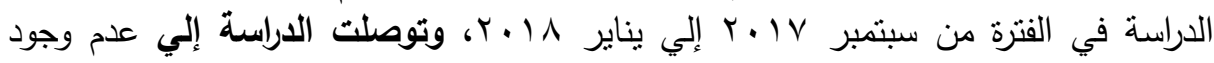

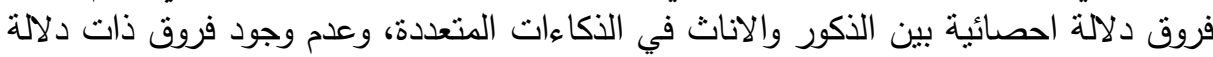

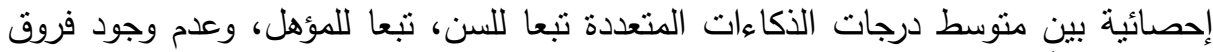

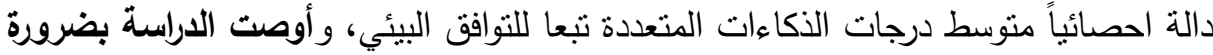

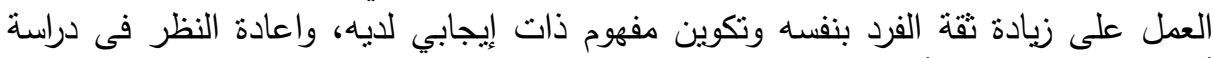

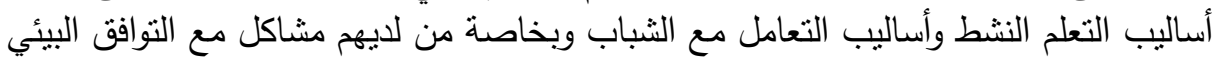
في بيئتهم الاجتماعية والتعليمية.

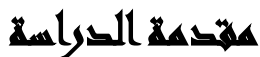

يثهد العالم اليوم تغيرات أساسية في جميع جواب الحياة، وذلك بسبب التسارع الحاصل

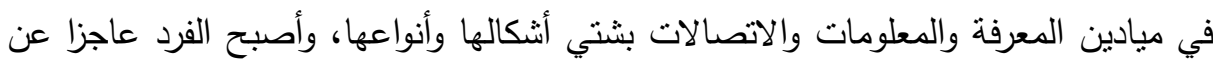

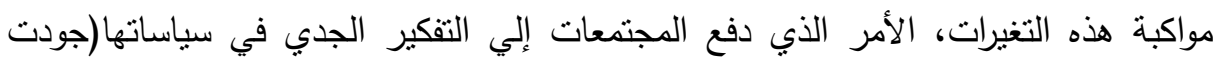

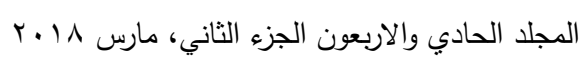




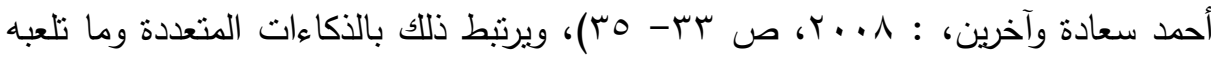
من دور في توافق الانسان مع بيئته، والانسان ذو الذكاء المتعدد يتميز بالقدرة على إدراك

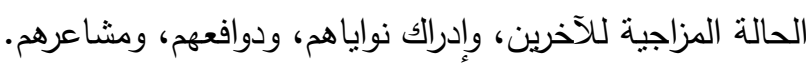

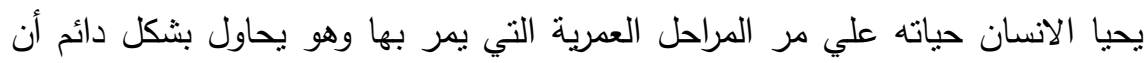

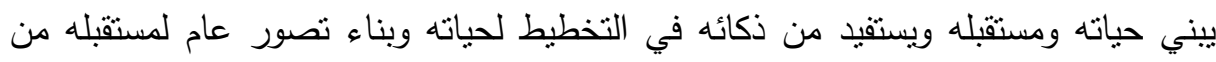

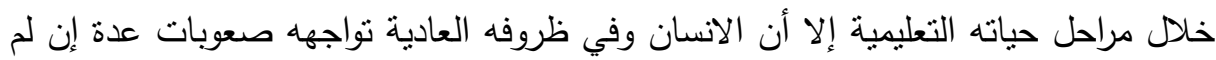

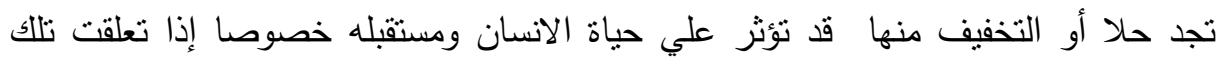
الصعوبات بشخصيته وما لذلك من أثر علي حالة التوافق التي يعيشها.

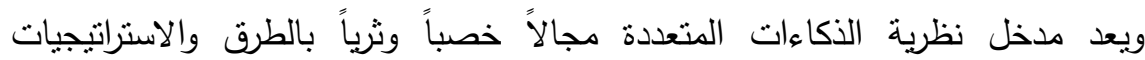
التدريسية المنتوعة والتي تمكن المعلم من تقديم المفاهيم العلمية لطلابه بصورة ذات معنى بطى تشبع احتياجاتهم وتحول الفصل الدراسي إلى عالم حقيقي للتنلاميذ . وحيث أن معظم الدول سواء كانت متقدمة أو تسعى للتقدم تعمل على تطوير بهرئ برامجها التعليمية، والعمل الجاد على إيجاد المواطن المفكر المبدع القادر على التعامل مع الحياة بنجاح لذا يجب أن تقدم الموضوعات بطرق منتوعة باستخدام أنشطة وأساليب متعددة تنتاسب

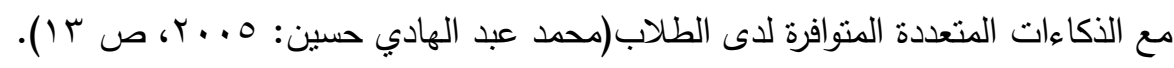
وقد منلت نظرية الذكاءات المتعددة نوجهاً جديداً تجاه طبيعة الذكاء مما شكل تحدياً واضحاً للففهوم الثقليدي للذكاء، ذلك الففهوم الذي لم يعترف إلا بشكل واحد من أشكال الذكاء، يظل ثابتا لاى الفرد في مختلف مراحل حياته، فقد وسعت نظرية الذكاءات المتعددة

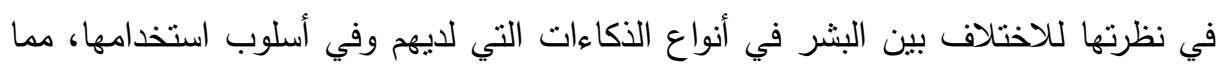

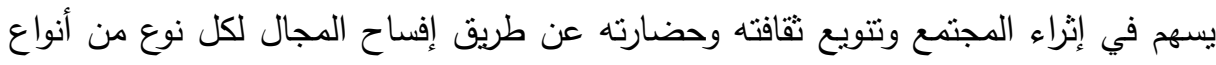
الذكاءات المتعددة بالظهور والتبلور في إنتاج ذي معنى يسهم في تطويره وتقدمه. (Checkley, Kathey (1997) : p .p - 8 : 13)

وقد حدد جاردنر سبعة أنواع من الذكاءات في البداية هي : الذكاء اللغوي، الذكاء المنطقي الرياضي، الذكاء الدكاني، الذكاء الجسمي الحركي، الذكاء الموسيقي، الذكاء

$$
\text { المجلد الحادي والاربعون الجزء الثاني، مارس ^م ـ ب }
$$


الاجتماعي، الذكاء الثخصي، ثم أضاف إليها نوعين آخرين هما: الذكاء الطبيعي، والذكاء الوجداني.Gardner, H. (1991). وتمنل نظرية جاردنر أهمية قصوى في وقتتا الراهن، فهي لا تقدم توجها جديدا لدراسة طبيعة الذكاء الإنساني فحسب، وإنما تقدم مداخل تعليمية هامة تتناسب مع طبيعة المتعلمين وأنماط تعليمهر من جهة، وطبيعة وخصائص المعلمين والفروق بينهم من جهة ثانية، والتغيرات

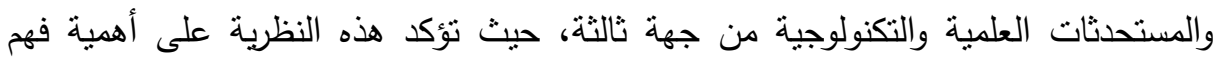
المتعمين للمنهج الأساسي والمحتوى الأكاديمي بشكل حقيقي بينطيعون من خلاله تطبيق معرفتهم في مواقف جديدة في حياتهم، مع ضرورة تحسين فهمه من خلال استخدام طرائق

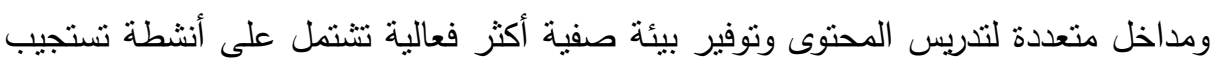

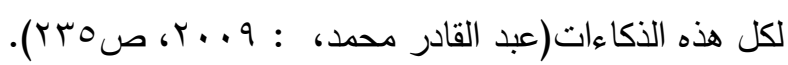

\section{هو}

هدفت دراسة عناقرة والجراح ه 1 ـ r إلى التعرّف على مسنوى عادات العقل والذكاءات المتعددة والعلاقة بينهما لدى عينة من طلاب السنة التحضيرية بجامعة طيبة، ولتحقيق هذه

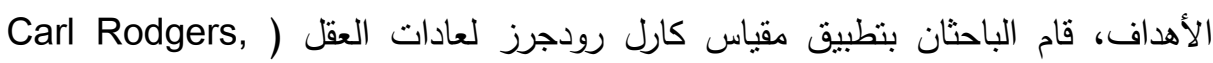

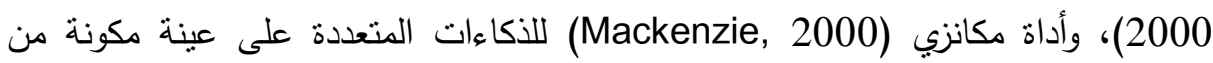

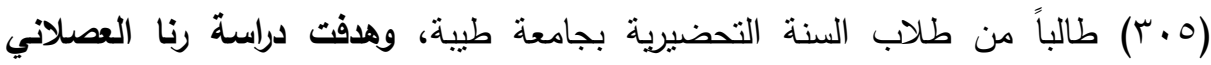

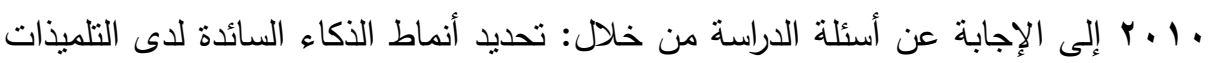

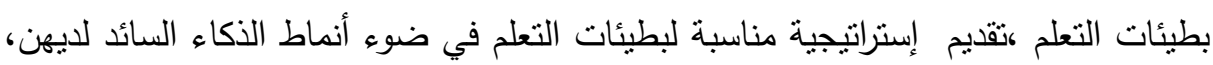

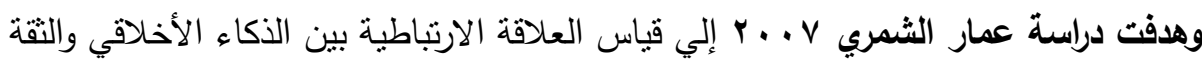

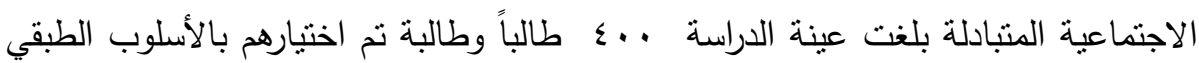
العشوائي من ثماني كليات من جامعة بغداد، وقام الباحث ببناء مقياساً للذكاء الاخلاقي لطلبة

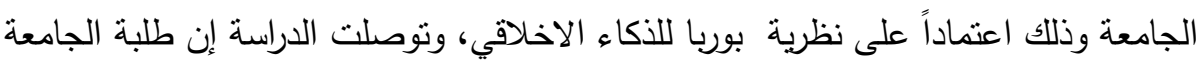
يتمتعون بذكاء أخلاقي، ووجود علاقة ارتباطية موجبة ذات دلالة إحصائية بين الذكاء

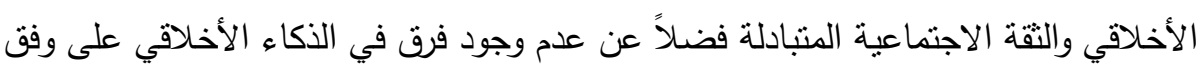

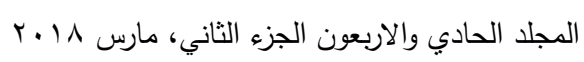


متغيري النوع ذكور - إناث، وهدفت رنا قوشحة ب... ف في دراستها إلى معرفة الفروق بين

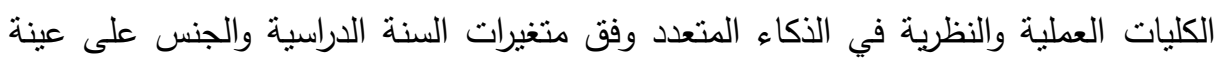

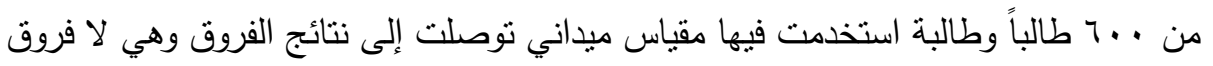
دالة بين طلبة الكليات العملي والنظري حسب متغيري السنة الدراسية والنوع بالذكاء الموسيقي رغم اختلاف ترتيب الذكاء بينما كانت الفروق لصالح الكليات العملية في الذكاء الحركي بلهي والمكاني واللغوي والاجتماعي والثخصي.

من العرض السابق يتضح أنه يمكن للأكاءات المتعددة أن تؤثز بشكل واضح في حياة الانسان من خلال علاقتها بالمتغيرات الثخصية والتوافق البيئي. ويمكن صياغة مشكلة الاراسة في التساؤل الرئيس التالي: ما العلاقة بين متوسطات الئئ

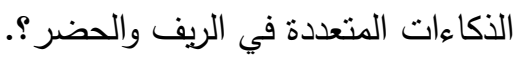

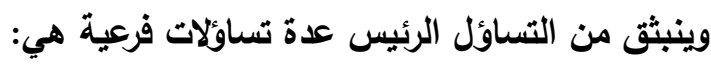
1- ما العلاقة بين درجات المجموعتين في الذكاءات المتعددة تبعا للمتغيرات الثخصية

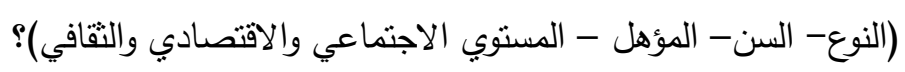
ץ- ما العلاقة بين درجات المجموعنين في الذكاءات المتعددة تبعا للتوافق البيئي ( الدافعية -

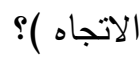

ومن العرض السابق أى الباحثون ضرورة التحقق من العلاقة بين الذكاءات المتعددة والمتغيرات الثخصية والتوافق البيئي بالتطبيق علي عينة ريفية وأخري حضرية من خلون خلال:

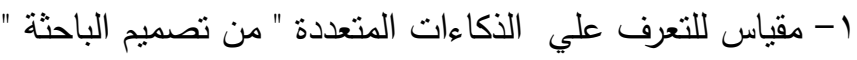
- مقياس المستوي الاجتماعي والاقتصادي والتقافي للعينة " من تصميم الباحثة".

\section{هزوضر الصواسما}

الفرض الرئيس: توجد فروق ذات دلالة إحصائية بين متوسطات الذكاءات المتعددة في الريف والحضر . وينبثق من الفرض الرئيس عدة فروض فرعية هي: 
1- توجد فروق ذات دلالة احصائية بين درجات المجموعتين في الذكاءات المتعددة تبعا

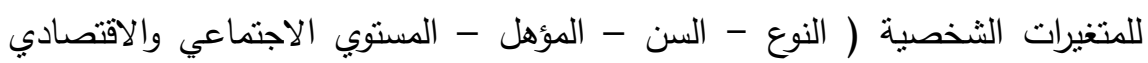
والثقافي). ץ- توجد فروق ذات دلالة احصائية بين درجات المجموعتين في الذكاءات المتعددة تبعا للتوافق البيئي ( الدافعية - الاتجاه ).

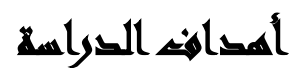

1- الكثف عن العلاقة بين الذكاءات المتعددة والمتغيرات الثخصية والتوافق البيئي بالتطبيق علي عينة ريفية وأخري حضرية.

\section{أهمري التواسمة}

- تقيد الدراسة في التعرف علي العلاقة بين الذكاءات المتعددة والمتغيرات الثخصية والتوافق البيئي. - تهنم هذه الدراسة بالذكاءات لما لها من أثر في حياة الفرد ومستوي طموحه ونجاحه.

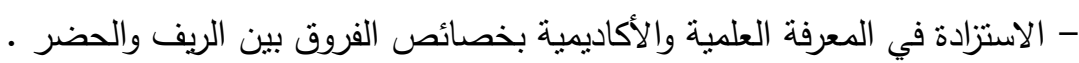
- قلة البحوث والدراسات التي تتاولت موضوع الذكاءات المتعددة ( في حدود علم الباحثة). - توجيه الاهتمام بدراسة الذكاءات المتعددة بشكل مستفيض والإلمام بطبيعتها، ومجالاتها، ومكوناتها، وأدوات قياسها، والطرق والوسائل الفاعلة في التعامل معها.

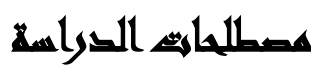

ا- نظرية الأكاءات المتعددة Multiple intelligences theory : تُعرف بأنها إحدى النظريات التربوية أو النماذج المعرفية الحديثة التي نستمد دعائمها من علم النفس الدعرفي وعلم النفس النمو، والتي جاءت كثورة للاعتراض على نظرية الذكاء الموحد التي

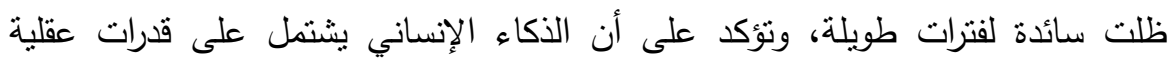

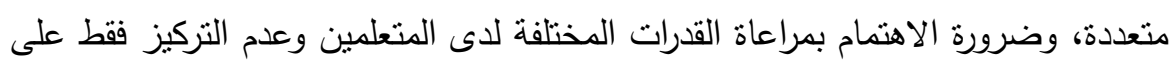

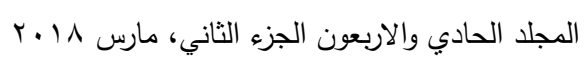


القدرات اللغوية والرياضية، كما تصف كيفية استخدام الأفراد ذكاءاتهم المتعددة لحل

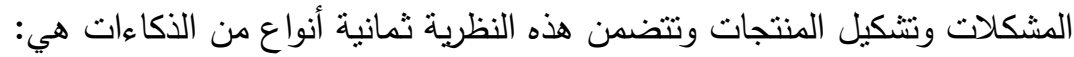

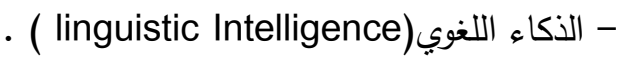
- الذكاء الرياضي المنطقي (Mathematical-logical Intelligence). - الذكاء الحركي الجسمي (Kinesthetic - bodily Intelligence). - الذكاء الثخصي (Intelligence personal). - الذكاء الاجتماعي (Intelligence Interpersonal) - الذكاء البصري المكاني (visual/ spatial Intelligence) - الذكاء الطبيعي (Intelligence Naturalist).

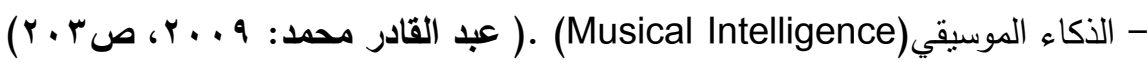
Y - مفهوم المتغيرات: يعرف (المتغير) في البحوث الاجتماعية على أنه الخاصية المميزة التى يمكن قياسها وتتخذ قيما مختلفة ومنتوعة في حالات فردية متعاقبة ويهتم الباحث بقياسها وبإيجاد العلاقة بينها، ومنها المتغير التابع والمسنقل والوسيط(أحمد شفيق

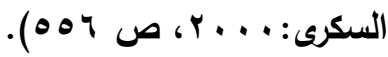

r - مفهوم المجتمع الحضري: جماعة إنسانية تككن بمنطقة عمرانية محددة وتتثارك منظومة من الوسائل التقنية، والنظم الددنية، والتتظيمات العمرانية، والأنشطة المتتوعة

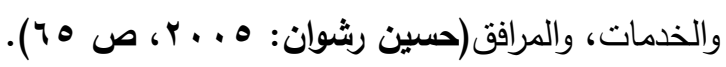

ع - مفهوم المجتمع الريفي: عُرف المجتمع الريفي فى الولايات المتحدة الأمريكية تعريفاً إحصائياً، وحسب حجم السكان، مما يمكن من تحديد المناطق الريفية، وحجم السكان غالباً ما تكون المعرفة به متاحة فى كثثر من البلدان، كما أن الحجم السكان تأثيراً ملحوظاً على أوجه الحياة الأخرى فى المجتمع المحلى. ويعرف البعض المجتمع الريفي بأنه " مجموعة من الناس تقيم فى منطقة محدودة والذين لديهم شعور بالانتماء بعضهم البعض والذين من خلال علاقتهم المنظمة يشتركون ويقيمون

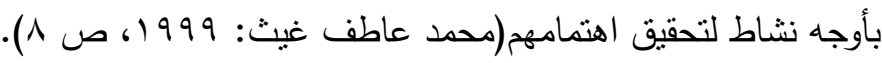




\section{صراسايت هابهي}

1- دراسة:- - كوستا وكاليك (Costa and Callick)

Costa, A. Kallicks, B. (2017). Habit - of - Mind. Retrieved, 23-72017, from http://www.docstoc.com/docs/15189296/Habits-of-mind أن العادة العقلية تتكون من عدد من المهارات والاتجاهات والقيم والخبرات السابقة والميول، وتتضمن معرفة كيف يتصرف المتعلم بذكاء عندما يكون لا يعرف الإجابة، فهي نمط من الأداءات الذكية تقود المتعلم إلى أفعال إنتاجية، نتيجة لاستجابة المتعلم إلى أنماط معينة من المشكلات والتساؤلات، شريطة أن تكون حلول المشكلات واجابات التساؤلات بحاجة

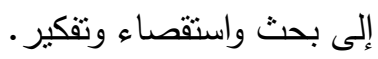

r - دراسة:- زهوة منير السيا حجاج: اسهام بعض المتغيرات في التتبؤ بالذكاء الأخلاقي لدي عينة من المكفوفين، رسالة ماجستير غير منشورة، معهة الاراسات العليا

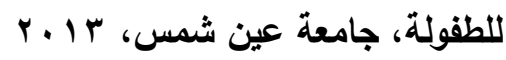

هدفت الدراسة الي التعرف علي اسهامات المتغيرات المنباينة سواء كانت بيئية أو اجتماعية في التتبؤ بالذكاء الأخلاقي عند المكفوفين مقارنة بذويهم من المبصرين، واعتمدت الباحثة علي المنهج التحليلي المقارن بالتطبيق علي عينة قوامها ل. . 1 مفردة من المبصرين والمكفوفين، وأوضحت نتائج الدراسة وجود تباين في المتغيرات التي تؤثر في مستوي الذكاء

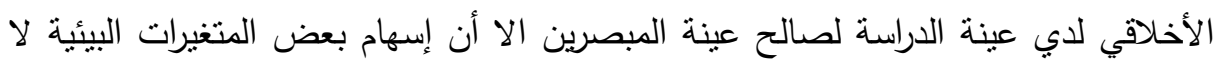
يختلف لصالح أي منهما.

r - دراسة:-موفق سليم صبح بشارة: أثثر برنامج تدريبي مستتد إلى نظرية بوريا في تنمية الأكاء الأخلاقي لدى أطفال قري S O S في الأردن، المجلة الأردنية في العلوم

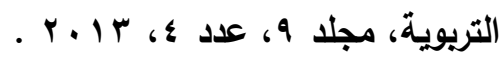

هدفت إلى التحقق من أثز برنامج تدريبي مستتد إلى نظرية بوربا في تتمية الذكاء

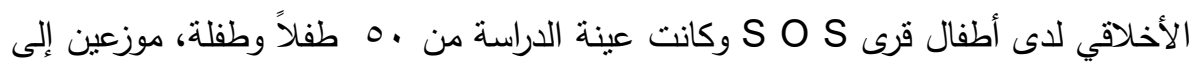

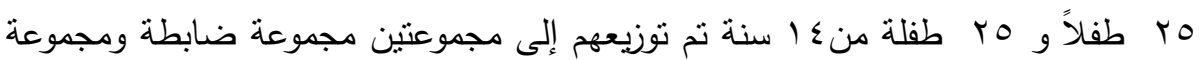

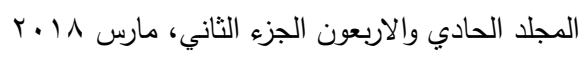


تجريبية، ولتحقيق أهداف الدراسة، بنى الباحث برنامج تدريباً في الذكاء الأخلاقي واستمر

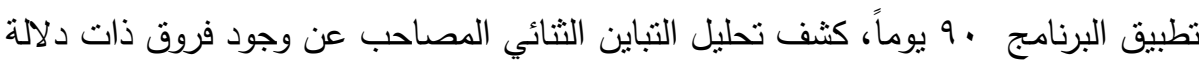

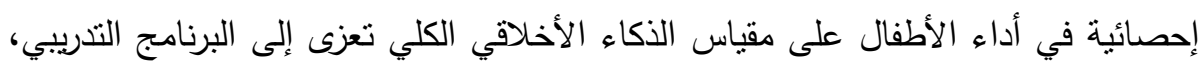

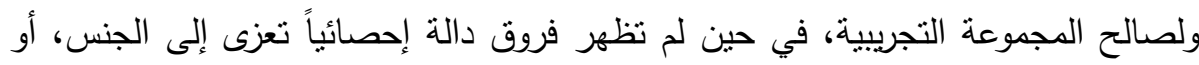
التقاعل بين البرنامج التدريبي والجنس.

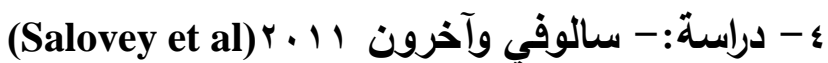

Mayer, j. \& Salovey, P. (2014). What is emotional intelligence? In P. Salovey \& D. Sluyter (Eds.). Emotional development and emotional intelligence: Implications for Educators. New York: Basic Books.

هدفت الدراسة إلي التعرف على القدرات العاطفية لعينة مقدارها 1 فرداً، باستخدام

الدقياس الذي أعده(Salovey \&Mayer) للأكاء العاطفي متعدد الأبعاد، وجدت الدراسة

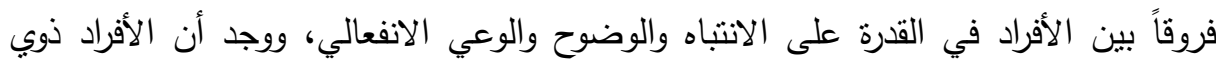

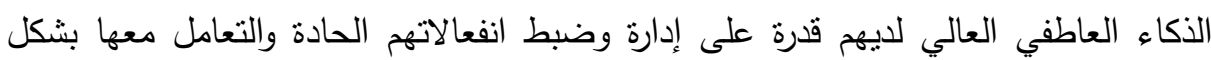
أفضل، ويتمتعون بصحة نفسية أفضل من الأفراد ذوي الذكاء العاطفي الأقل.

\section{الإلطار اللزظليه}

أولا:- مفهوم الأكاء: إن فكرة اختلاف الافراد في القرات هي فكرة مقبولة على نطاق واسع و بناءً على هذه الفكرة بمكن تسمية فرد بانه ذكي أو أكثر ذكاء أو أقل ذكاء، إن الاتفاق

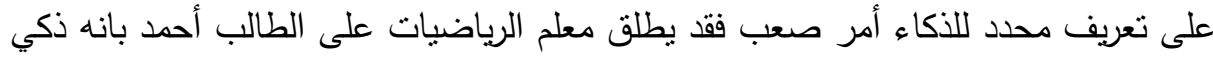

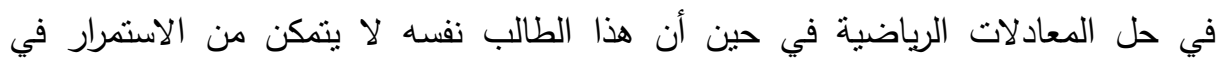
الحديث مع طالب آخر أكثر من (r) جمل . وقد صنف الأكاء الى خمسة تصنيفات وهي: - تعريفات تؤكد على تكيف الفرد مع الظروف التي يعيش فيها ومنها تعريف شترن: " بأنه

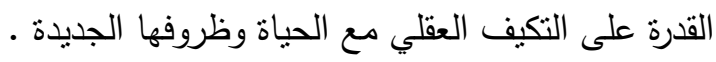


- تعريفات تؤكد على القدرة على التعلم و منها تعريف جوردن: " بانه القدرة على الاستفادة من الخبرات السابقة في المشكلات الجديدة.

- تعريفات تؤكد على التفكير ومنها تعريف تيرمان:" أنه القدرة على التفكير المجرد الذي يعتمد

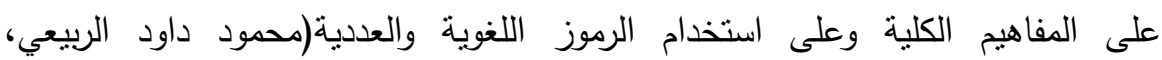

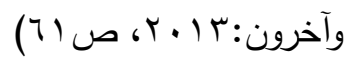
- تعريفات أكثر شمولاً وتجمع مجموعة من الوظائف العقلية التي يتسم بها السلوك الذكي

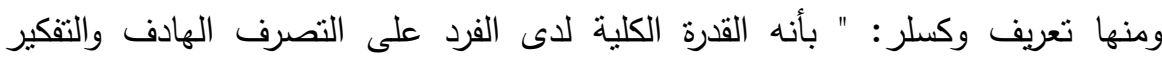
المنطقي والتعامل المجدي مع البيئة ".

وكذلك تعريف ستودارد: " الذكاء هو القدرة على القيام بأوجه مختلفة من النشاط تتميز

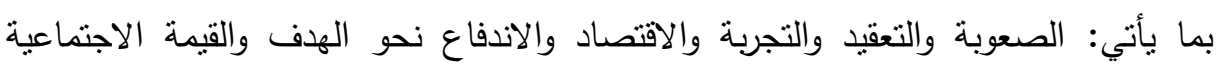
وظهور الابتكارات والاحتفاظ بهذه الاوجه من النشاط تحت ظروف تتطلب تركيز الجهد و والجه

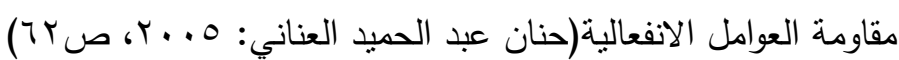
- تعريفات تحاول حسم الخلاف مثل تعريف بورنج : " الذكاء هو ما تقيسه الاختبارات

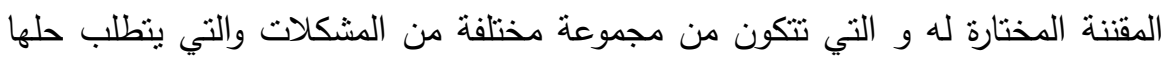

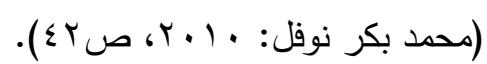

واختلفت تعريفات العلماء والمختصين للذكاء باختلاف خلفياتهم النظرية من وجهة

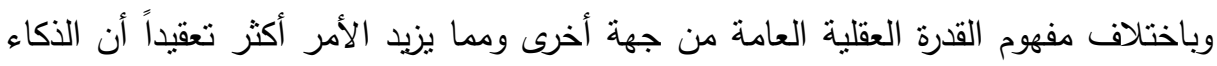

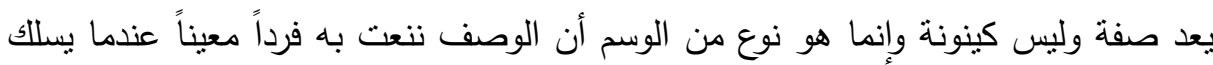

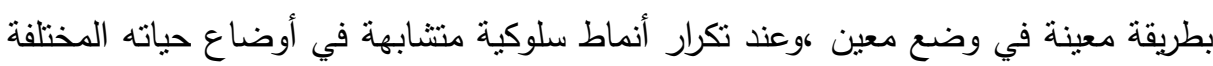

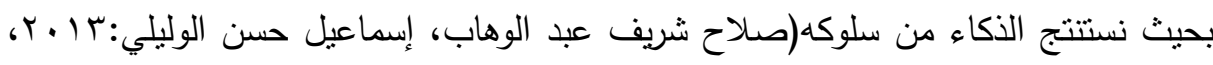

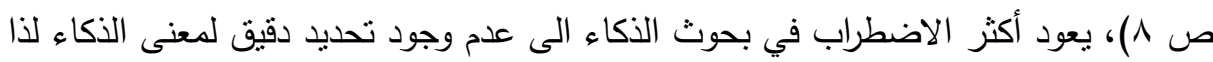
لا يمكننا أن نعالج الموضوع معالجة دقيقة مع الإثارة بان الذكاء في علم النفس مصطلح

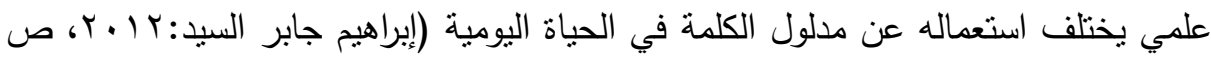
ـ ()، والذكاء صفة وليس شيئاً موجداً وجوداً حقيقياً فقد حاول الكثير من العلماء تعريف

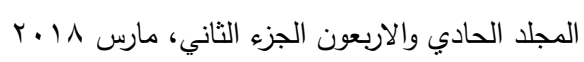


الأكاء أو تحديده كما لو كان شيئاً له وجود أو ككيان حقيقي والواقع أن الذكاء ليس أكثر من مجرد صفة مثل الجمال والأمانة وهي صفات يمكن قياسها ولكن لا يعني أن لها وجوداً فعلياً

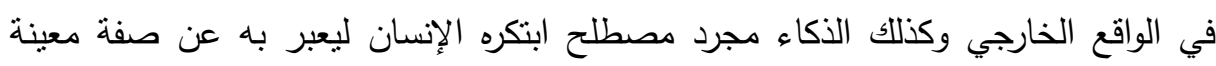

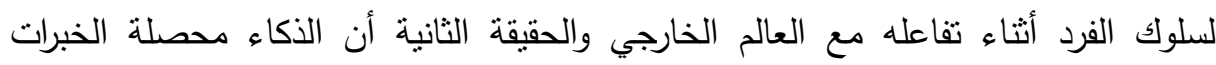
التعليمية للفرد فقد عرفة بيرت بأنه قدرة معرفية فطرية عامة وكل المواقف التي نلاحظ فيها

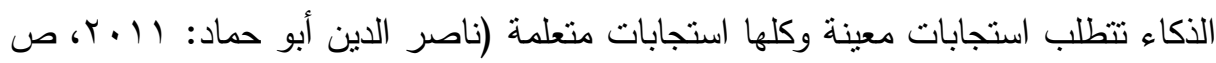

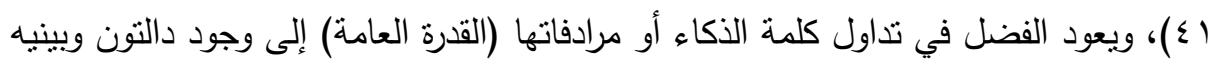

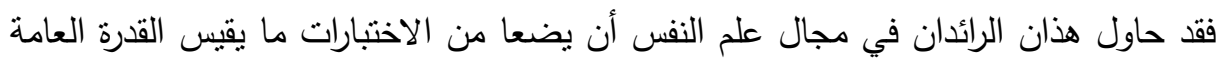

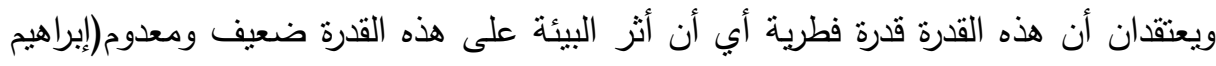

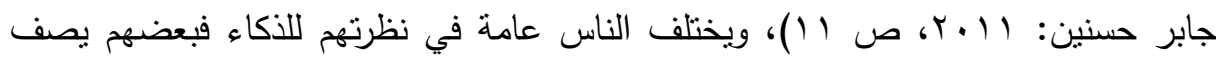
الذكي بأنه ذو اليقظة وحسن الانتباه والفطنة لما يدور حوله أو ما يقوم به من أعمال ومنهم من يراه الثخص الذي يقدر عواقب أعماله ولديه القدرة على التبصر ومنهم من براه الثخص وله

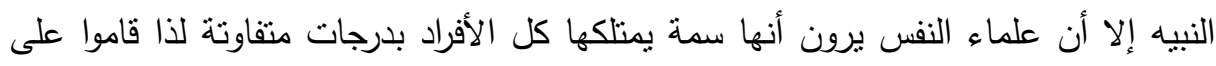

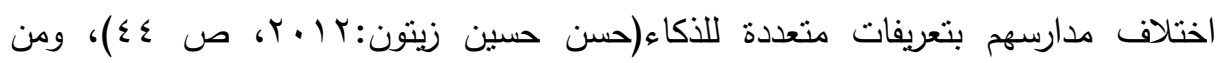
المتعارف إن الذكاء هو القدرة على مواجهة الصعاب، ومهارة التكيف مع الظروف الطارئة من

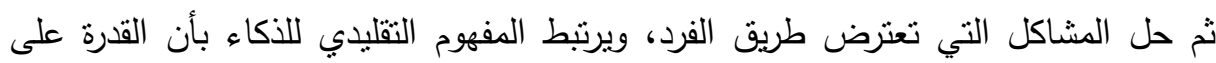
التفكير والاستتناج المنطقي والنهج العقلي والقدرة على خزن المعلومات وهي بهذه الصورة قدرة

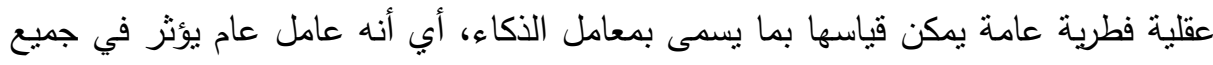

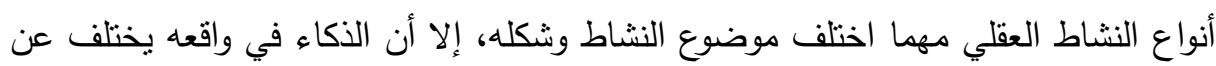
ذللك فالذكاءات موجودة لدى كل فرد ولكنها موجودة بتفاوت مما يجعل مفهوم الذكاء أكثر

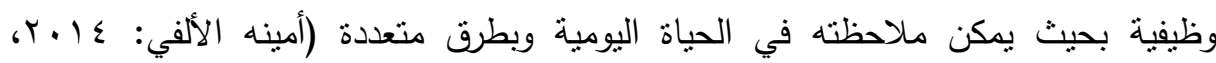

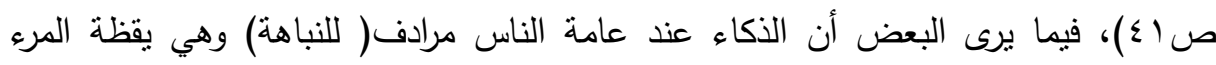

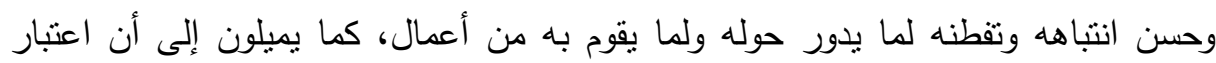
الذكاء قدرة عامة شاملة يبدو أثرها في ميادين مختلفة، وبالرغم من أن نسبة الذكاء ودرجته

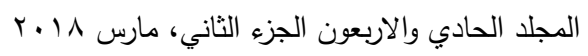


تختلف من شخص لآخر ، إلا أن الثابت أن لكل فرد درجة من الذكاء تميزه عن غيره فلا يوجد فرد عقله صفحة بيضاء، كما يتضمن عدد من القدرات العقلية الفرعية منها القدرة الرياضية

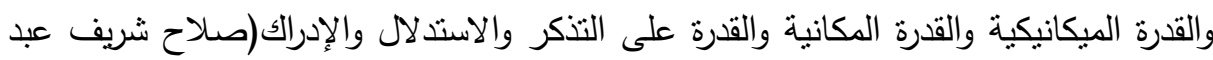

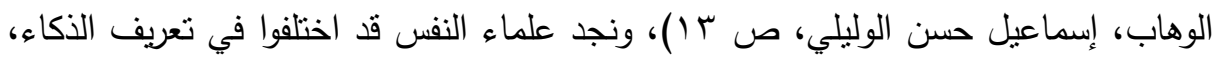
فمنهم من عرفه حسب وظيفته وغايته ومنهم من عرفه حسب بنائه التكويني ومنهم من عرفه إجرائيا.

فعرف بينيه Binet الذكاء بأنه هو الميل أو القدرة على اتخاذ وجهة محددة والحفاظ عليها والاستمرار فيها والقدرة على التكيف من أجل الوصول إلى الهدف المطلوب، والقدرة على النقد الذاتي، ويرى أن الذكاء يتكون من مجموعة من الخواص تضمن الاهتمام بمشكلة وتوجيه العقل نحوها، والقدرة على التكيف بأقصى قدر ممكن للوصنول إلى نهاية محددة والقوة

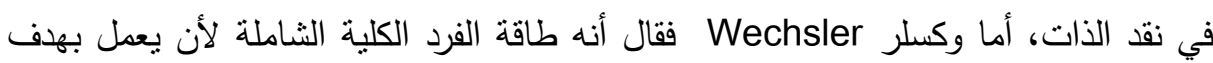

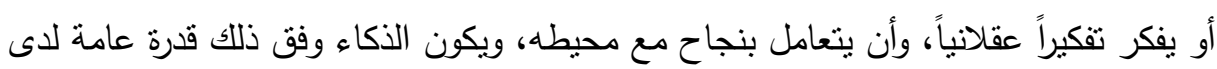

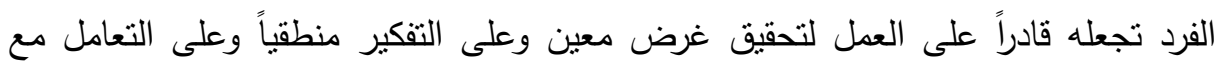

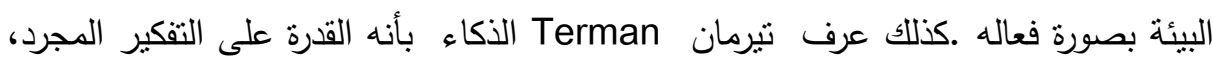
أما العالم همفري Humphrey فعرف الذكاء بأنه هو المجموع الكلي للمهارات المكتسبة والمعارف والاستعداد للتعلم والقدرات التي تعبر عن عمليات ذهنية في طبيعتها والتي تتوفر هورف

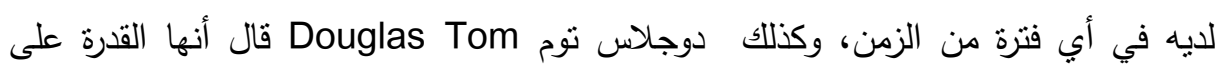

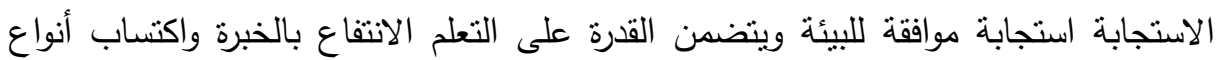
مهارة وجمع المعلومات وتتظيم ذلك كله في أثنكال وصور نافعة وحلقات متتاسقة تسهم في

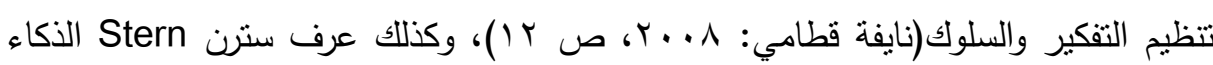
بالقدرة العامة على التكيف العقلي للمشاكل ومواقف الحياة الجديدة والقدرة على التصرف السليم

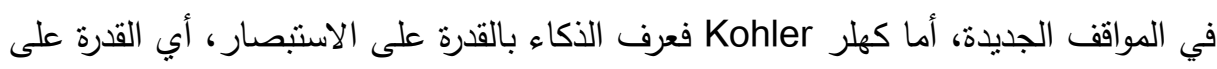
الإدراك أو الفهم الفجائي بعد محاولات فاثلة تطول أو تقصر ، وجورداد عرفه بأنه هو القدرة على الاستفادة من الخبرات السابقة في حل مشكلات حاضرة والتتبوء بمشكلات مستقبلية

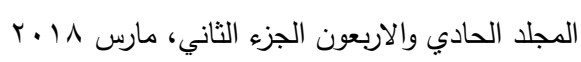


ودرجة انتفاع الفرد من خبراته في حل المشكلات واكتشاف العلاقات .أما تعريف سبيرمان

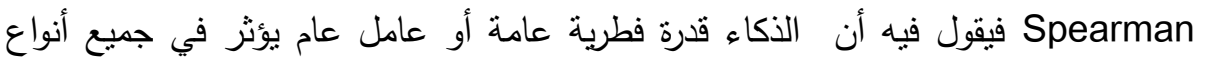

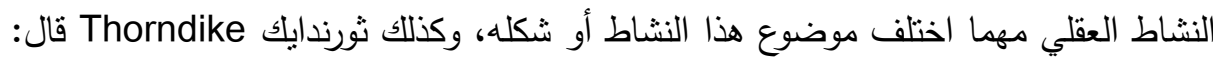
هو محصلة (منوسط حسابي) لعدة قدرات مستقلة عن بعضها البعض وينفي نورندايك وجود

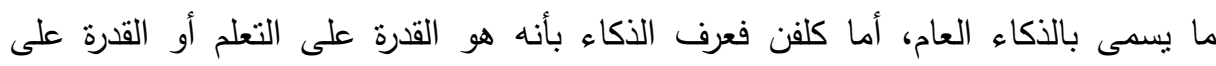

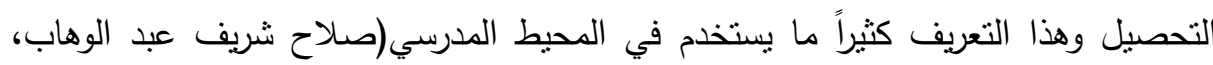
إسماعيل حسن الوليلي، ص r Y)، وأخيرا نطرق الى تعريف جاردنر للذكاء حيث يرى جاردنر

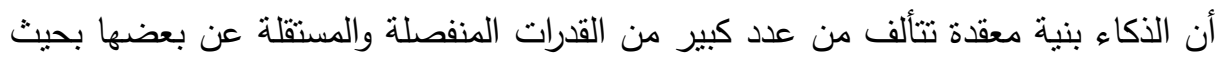

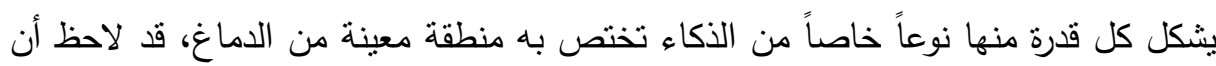

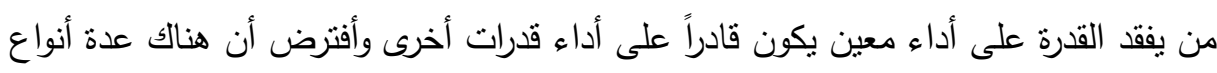

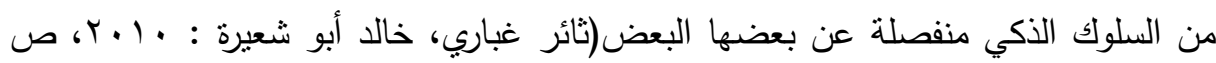

فالاعتقاد السائد هو أن الذكاء في جوهرة يستمر مع الإنسان مدى الحياة، وأن التلميذ الذي يمنلك قدرات ذكائية أفضل من غيره تنقى ثابتة لديه وغير قابلة للتعديل أو التغيير ولكن الإن فئن

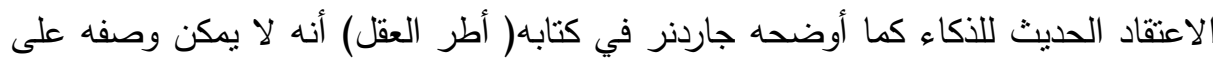
أنه كمية ثابتة يمكن قياسها، وبناء على ذللك يمكن زيادة الذكاء وتتميته بالتدريب

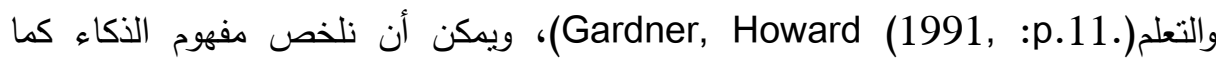

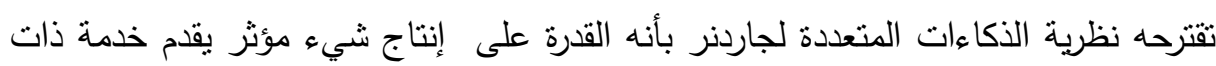
قيمة في الثقافة ومجموعة من المهارات الني تمكن الثخص من حل المشكلات بطريقة جيدة بندانه وإمكانية إيجاد حلول للمشكلات تمكن من حشد معارف جديدة (محمد عبد الهادي حسين:

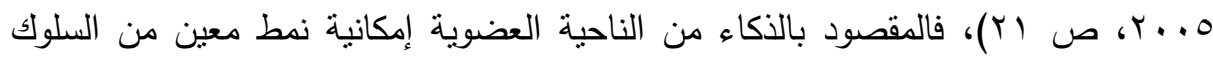

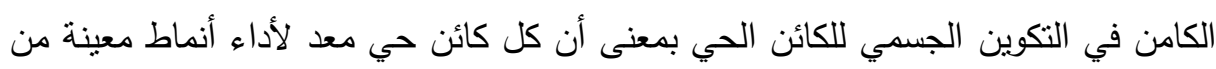

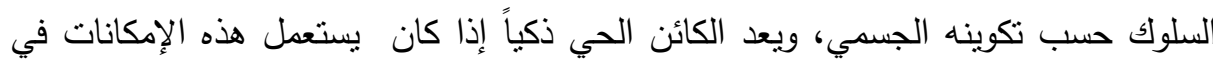
المواقف التي تدعوه لاستعمالها، أي أنها قدرة موروثة تتضمن وجود فروق في درجة استعمال

$$
\text { المجلد الحادي والاربعون الجزء الثاني، مارس ^| • ب }
$$


هذه الإمكانات بين الكائنات الحية في الجنس الواحد، أما من الناحية الاجتماعية فإن الذكاء

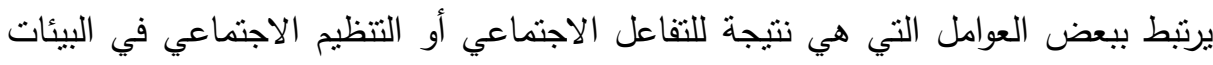

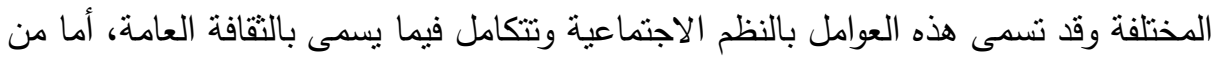
الناحية السلوكية أو النفسية فالمقصود بالذكاء نمط السلوك الذبي يحدده نوع معين من النئه الاختبارات ونمط السلوك في الاختبار دليل على السلوك في الحياة العامة(إبراهيم جابر السيد،

ثانيا: الأكاعات المتعددة: في عام rه19 قدم العالم الأمريكي هاورد جاردنر كتابه الذي

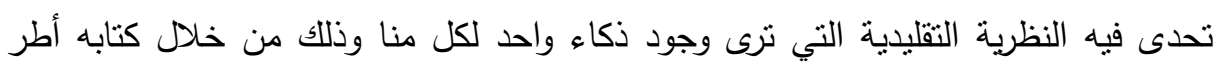
العقل (Frames of Mind) وفيها كثنف عن أنه يوجد لدى كل منا أنواع مختلفة من

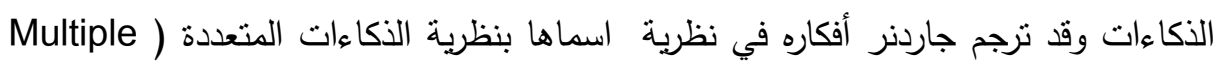
(Intelligence Theory

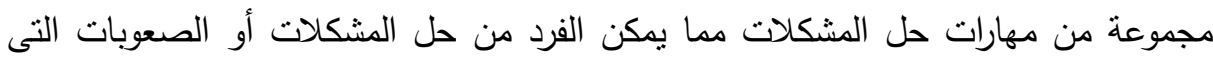
تقف في طريقه وتمكنه من خلق نتاج فعال عندما يكون مناسباً لاكتساب معرفة جديدة(حسن من من من من

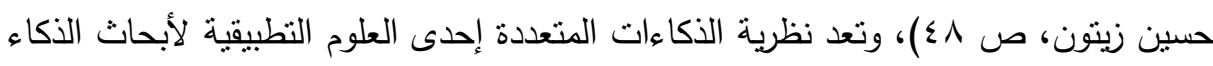
الإنساني حيث يكاد الآن على المستوى الدولي يتعاظم دور هذه النظرية فئندية في نطور التعليم

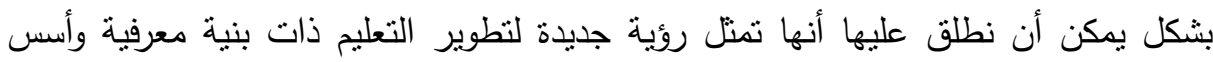

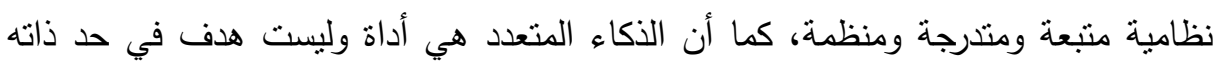

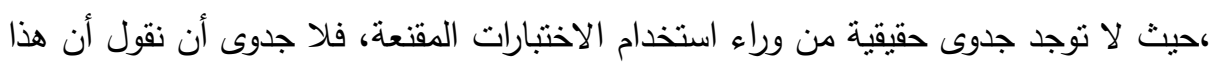

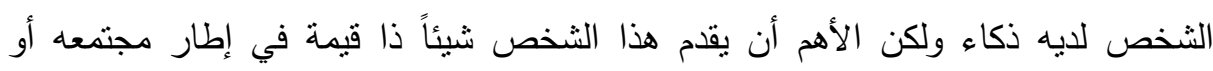
ثقافته(محمد عبد الهادي حسين، ص 7 (1)، وقد سعى جاردنر في نظريته عن الذكاء المتعدد

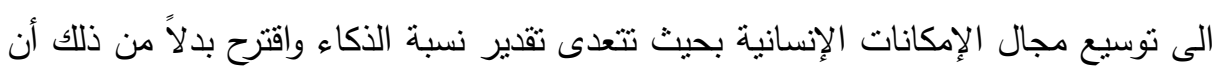

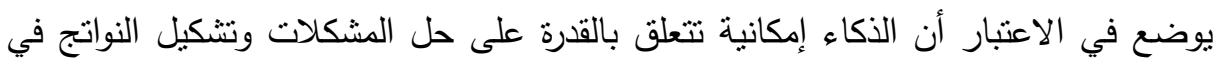

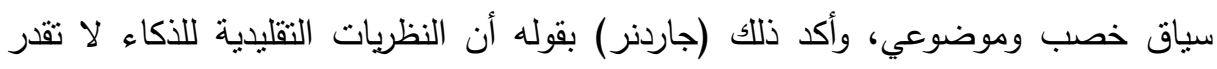
الذكاء الإنساني بطريقة مناسبة من خلال اختبارات الذكاء التقليدية لأنها تعتمد على معدل

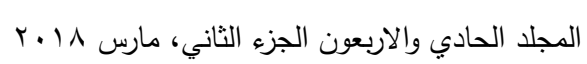


قليل من القدرات العقلية، بالإضافة إلى أنها ليست عادلة، حيث تتطلب من الأفراد حل المشكلات بصورة لغوية أو لفظية فقط فعلى سبيل المثال نجد أن الاختبارات التى تقيس القدرة

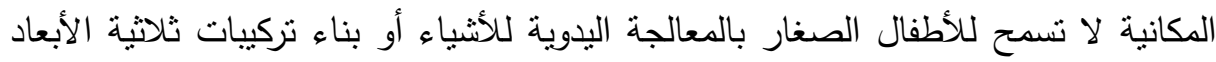

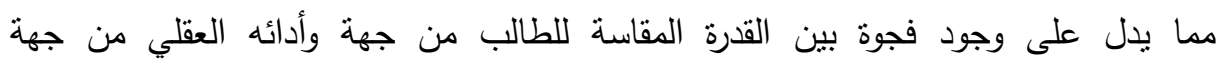
أخرى(صلاح شريف عبد الوهاب، إسماعيل حسن الوليلي، ص 9 (1)، وتعتبر نظرية جاردنر

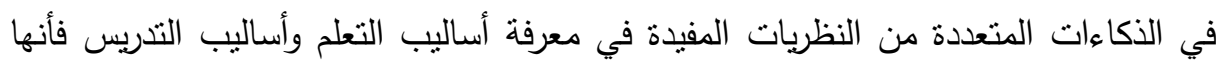
تكتثف مواطن القوة والضعف عند المتعلم .حيث أن كل شخص متميز عن الآخرين، فالذكاء

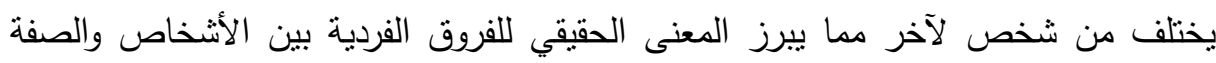

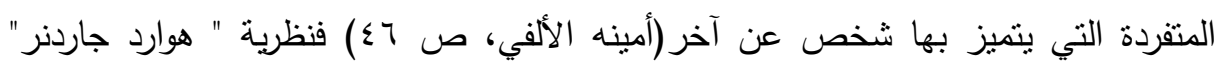

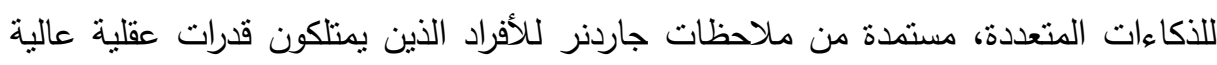

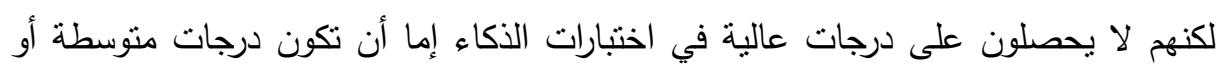
متدنية، وبالتالي لفتت انتباه جاردنر أن الذكاء مكون من ذكاء فات فتات متعددة وكل ذكاء يعمل

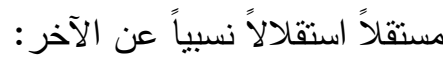
1- الأكاء الاجتماعي: ترجع الجذور القديمة لهذا المفهوم مع بداية الثنالثنيات حيث نادي الائي "ثورنديك" (·Thorandike, 19r) بضرورة توسيع مفهوم الذكاء العام ليشمل قدرات

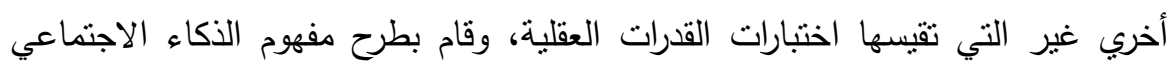

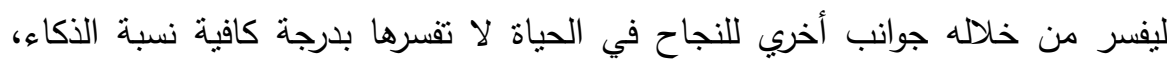
وعرفه بأنه:" القدرة على فهم الآخرين، والتصرف بحكمة في المواقف الاجتماعية".

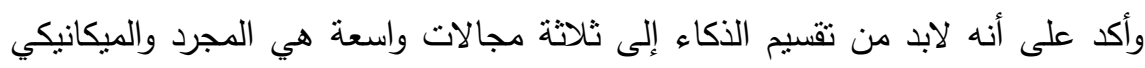
والاجتماعي لكي ينت وصف وقياس ذكاء الفرد بشكل أكثر شمولية.

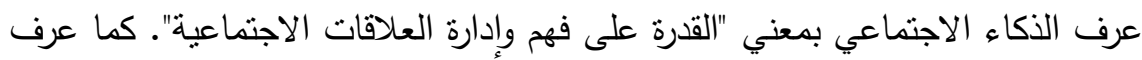
المكون السلوكي بأنه "القدرة على التفاعل بشكل أكثر حكمة في العلاقات الإنسانية". 
ولعل "سبيرمان، Spearman" كان على نفس الدرجة من البصيرة، حيث اقترح عام

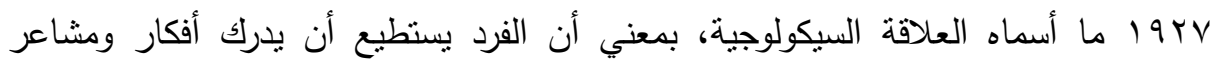

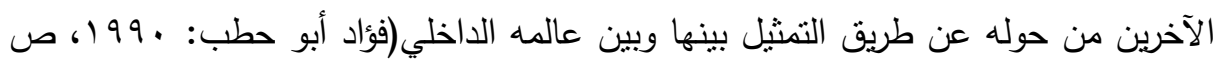
. ( $\{\cdot 1$

يتضح من تقسيم "ثورنديك"- وهو أول من أهتم بوجود ذكاء آخر غير الذكاء العقلي أو

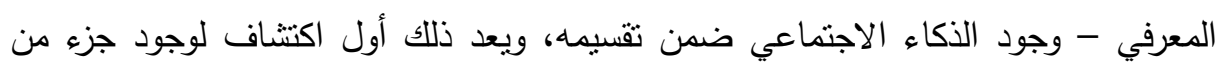
مفهوم الذكاء الوجداني، وهو (القدرة على فهم الناس والتفاعل معهم)، واتفق سبيرمان فيما أسماه

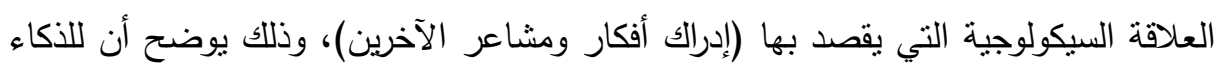
الوجداني جذور في تراث علم النفس. واجه مفهوم الذكاء الاجتماعي عدة مشكلات نتيجة اتساع الدفهوم وفقدانه البعد التجريبي ومشكلات قياسه والمزج بين عدة مفاهيم كالثخصية والاتجاهات وتقديمها على أنها الذكاء الاجتماعي حيث اهتم بالقدرة على فهم الآخرين وإقامة العلاقات الاجتماعية واتجاهات

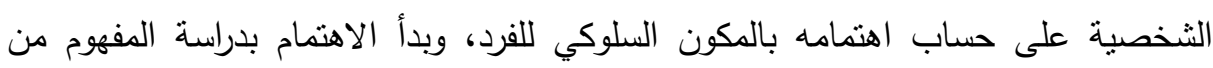

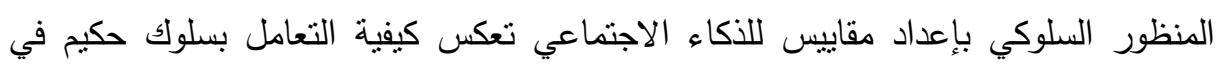

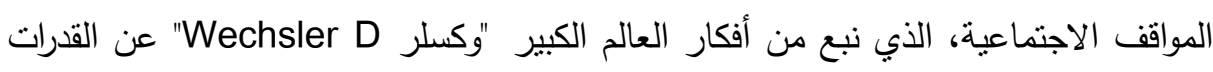
غير المعرفية في عام •ـ 19 وأن الذكاء حاصل جمع الجوانب العقلية والجوانب غير العقلية، ثم أكد في عام (بـ 9 1) على الجوانب الوجدانية والثخصية والاجتماعية ضرورية للتنبؤ بقدرة

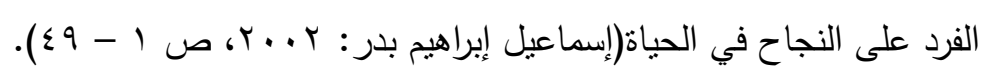

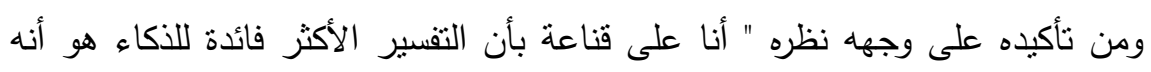

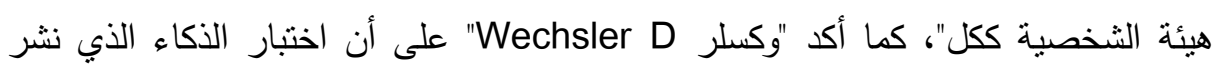

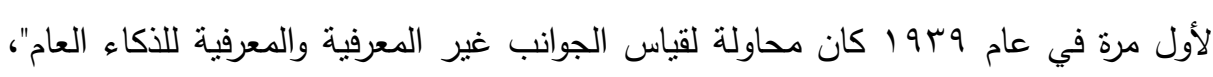
حيث كثف التحليل العاملي لهذه الاختبارات أنها تفسر • ٪\% من التباين الكلي، أما التباين المتبقي فيرجع إلى عوامل أخري غير معرفية. 
عرف "وكسلر Wechsler D., 1958 الذكاء بأنه "قدرة الفرد الكلية الثاملة على التصرف بقصدية، والتفكير بعقلانية، والتعامل مع البيئة بفاعلية، وأنه من الذكاء أن يتأقلم

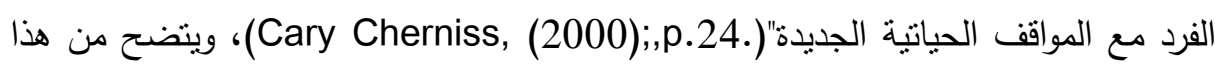
التعريف أن الأفراد يتباينون بوضوح في قدراتهم الفعالة على مواجهة التحديات والمتطلبات البيئية. كما أثنار إلى ضرورة النظر لحياة الإنسان بأحداثها وتفاعلاتها المركبة.

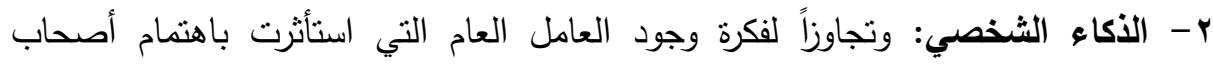
المناحي السيكومترية للأكاء، وتأكيدهم على العوامل المعرفية مقارنة بالعوامل الانفعالية

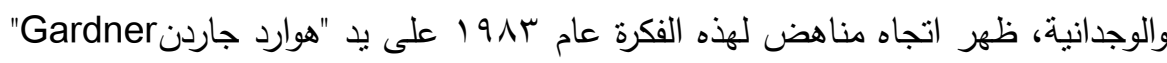

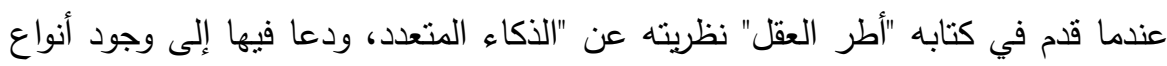
متعددة ومستقلة من الذكاء، ومنها: الذكاء اللغوي، والذكاء المنطقي- الرياضي، والذكاء

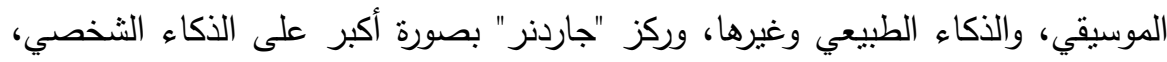

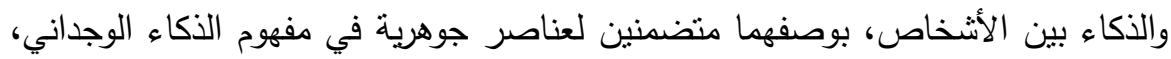

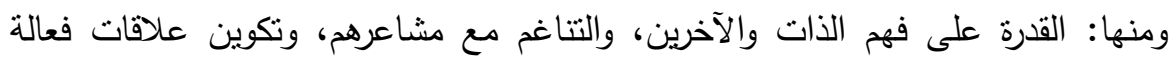

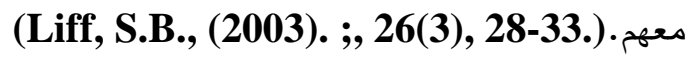

إن نظرية الذكاءات المتعددة تلعب دوراً هاماً في المجال التعليمي من حيث اكتثاف المتفوقين وصياغة المناهج وطرق التدريس لمقابلة احتياجات وميول واستعدادات التناميذ بل هل

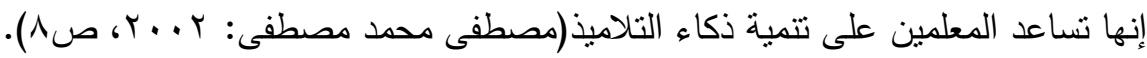
كما ساعد بعد نظرية "هوارد جاردنر Gardner" عن المفهوم الأحادي لقياس معدل

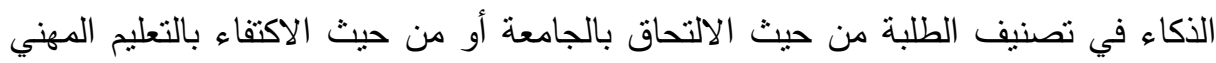
وفتحت آفاقاً جديدة للأخذ بعين الاعتبار للمهارات والقدرات الثخصية للطلاب واكتشاف أوجه الهاء الكفاءة لتتميتها وأوجه القصور لمعالجتها. كان هذا الفكر مدعاة إلى بلورة مفهوم الذكاء الثخصي على المستوي العربي على يد "فؤاد أبو حطب" بداية من عام سلو19 وحتى .199 حيث شارك مع العديد من الباحثين على دراسات "جاردنر" - في الاهتمام بعنصر الذكاء الثخصي. 
قام بتقسيم الذكاء إلى ثلاثة أنواع: المعرفي والاجتماعي والوجداني، وقد ظل هذا النموذج

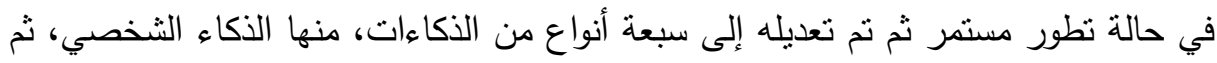
استقر على التصنيف الثلاثي في عام برد19 في نموذج العمليات المعرفية النفسية (الموضوعي Objective Impersonal - الثخصي Intrapersonal- والذكاء بين الأثخاص Interpersonal - Social Intelligence).

وقصد بالذكاء الثخصي "استراتيجيات عملية التفكير ، والتي تتحول إلى مهارات تكتسب بالتعلم وتختزن في الذاكرة في صورة كفاءات مضمونها المعلومات الثخصية المتصلة

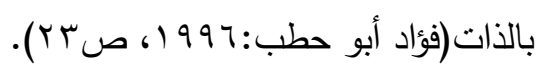

r- الأكاء اللغوي: يعد الذكاء اللغوي أحد مكونات نظرية جاردنر ويرى أنه من الممكن التعرف على هذا الذكاء لاى فرد ما من خلال مؤشرات واضحة منها القدرة على الحفظ

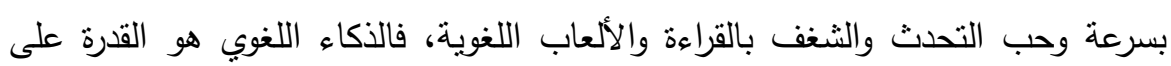
نوليد اللغة والتراكيب اللغوية التي تتضمن الثعر وكتابة القصص واستعمال المجاز والشغف بالكلمات والثغف باكتساب اللغات والقدرة على توظيف اللغة لأهداف مختلفة واستخدام اللغة للتعبير والتواصل والإقناع وطرح المعلومات والأفكار وليس فقط إنتاج اللغة ولكن حساسية عالية للفروق الطفيفة بين الكلمات وترتيب وسجع الكلمات، كما أنها تعني المقدرة على استخدام اللغة الأم وربما لغات أخرى بكفاءة في التعبير الثفهي( كرواية

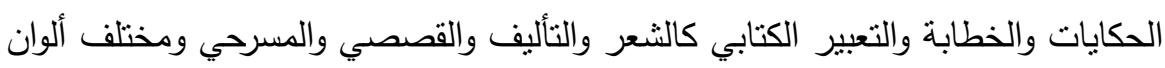
الكتابة من أجل التعبير عما يجول بالخاطر وفهم الآخرين ويتضمن هذا النوع من الذكاء

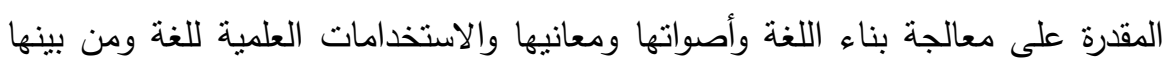

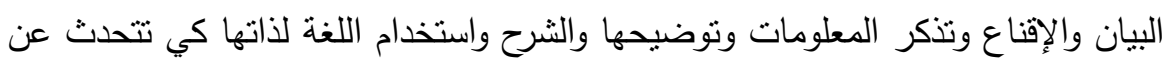

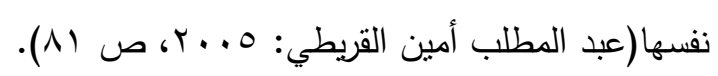

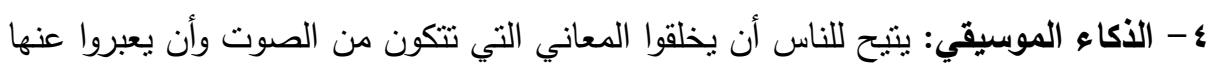

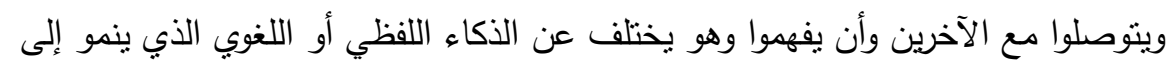
درجة عالية عبر التقافات من تعليم نظامي، ذلك أن الذكاء الموسيقي قد ينطلب تعرضا

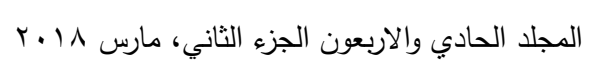


لهاً أكثر كثافة، وقليل من الأفراد يحققون مهارة عالية دون سنوات من التنريب، ودراسات

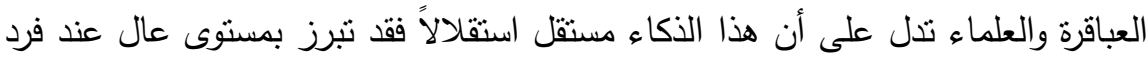
Capabilities

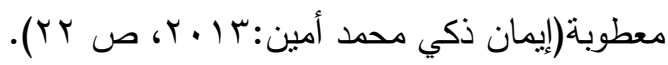
ه- الذكاء المنطقي الرياضي: يتضمن ويتطلب استخدام العلاقات المجردة وتقديرها، وتدعم بحوث بياجيه تطوره، ويبدأ الاستدلال المجرد في عملية استكثاف الأشياء أو ارتيادها، ويتقدم إلى نتاول الأثياء، وإدراك الأفعال التي يمكن القيام بها وإجراؤها وتكوين القضايا

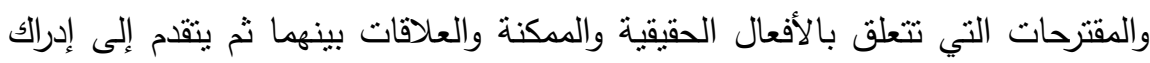
العلاقات في غيبة الفعل أو الأشياء والموضوعات وهذا التفكير المجرد.

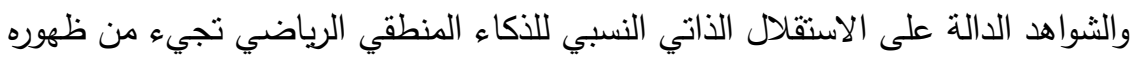

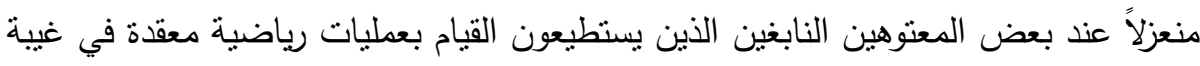
القدرات الأخرى ومنها حالة هنري ماندو الذي استطاع إخبار من يقابله عن أعمارهم بالثواني. ويتمنل هذا النوع من الذكاء على نحو واضح عند علماء الرياضيات ومبرمجي الكمبيوتر والمحللين الماليين، والمحاسبين والمهندسين والعلماء، ويظهر في الاستدلالات الفائقة في

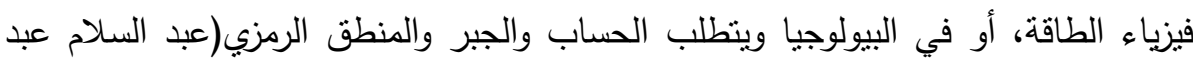

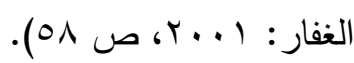

צ- الأكاء المكاني: يتتاول القدرة على إدراك المعلومات البصرية والمكانبة، وأن يحول ويعدل هذه المعلومات، ويعيد خلق الصور البصرية دون الإحالة أو الإرجاع إلى المثير الفيزيقي الأصلي، وهذا الذكاء مطلوب للعمل في حل مشكلات أو القيام بمهام كتنلك التي نجدها

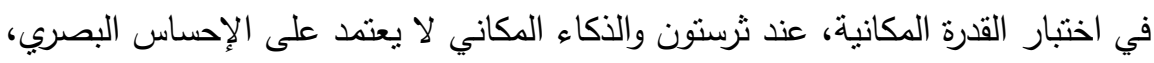

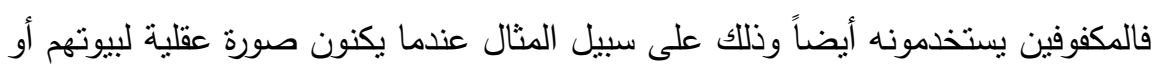

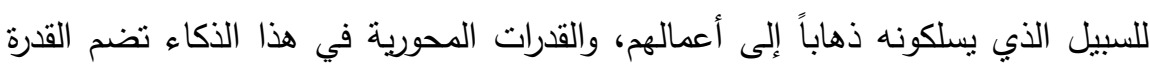

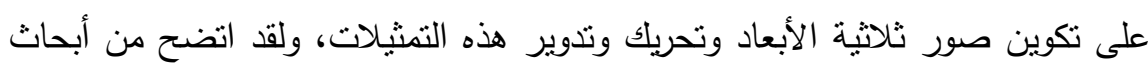

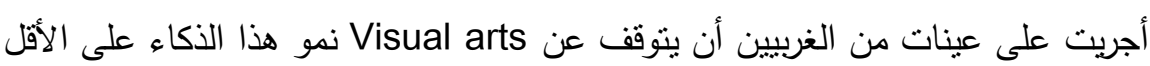

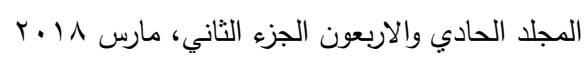


كما يطبق في الفنون البصرية النمو في الطفولة المنوسطة مالم يجد دعماً ومساندة وتعليماً يرعاه، غير أن هذا الذكاء ينمي ويهذب خارج الفنون البصرية وعلى سبيل المثال عند

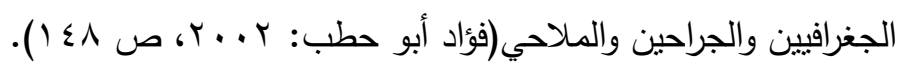
وعلى الرغم من أن المهارات الرياضية والمنطقية والمهارات المكانية تتمو نتيجة إدراك الأثنياء، إلا أن البحوث النيرولوجية تدعم استقلالية الذكاء الدكاني، يتطلب الأداء السليم

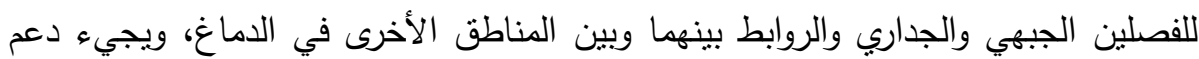

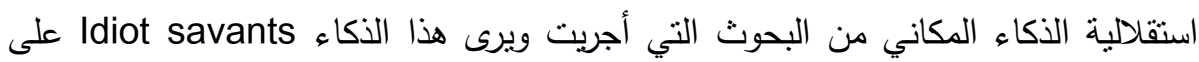
الأطفال المعجزة وعلى المعتوهين النابغين بوضوح في أعمال المعماريين والمهندسين الذين يظهرون قدرة مكانية متميزة، ويستدل عليه من سير المثالين المشاهير والفنانين الأفذاذ كمختار وبيكاسو ويقاس بواسطة اختبارات يبحث فيها المفحوصون عن الأشكال المختبئة في الرسوم أو الصور وفي التدوير العقلي للأشياء والأشكال في المكان، وفي وصف التغيرات التي نطرأ

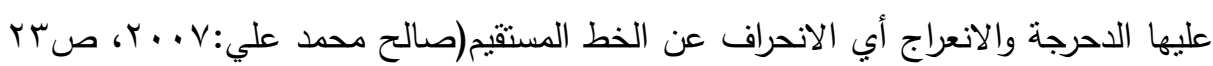
V - الذكاء الجسمي الحركي: ويبدو هذا الذكاء أكثر الذكاءات بعداً عن النظرة التقليدية للذكاء وتتضح في المهارة الفائقة التي يبديها منسلقو الجبال الوعرة والانحدارات الحادة والخبرة في لئهي

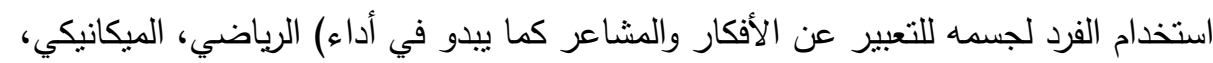
الجراح، (والعمليات المحورية التي ترتبط بهذا الذكاء هي السبطرة على الأفعال الحركية الكتلية

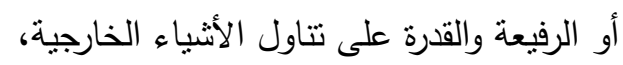
والأسس البيولوجية لهذا الذكاء معقدة وهي تضم الثآزر بين الأجهزة العصبية والعقلية

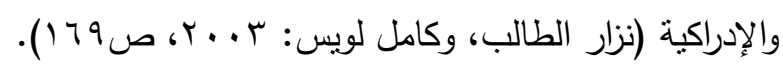

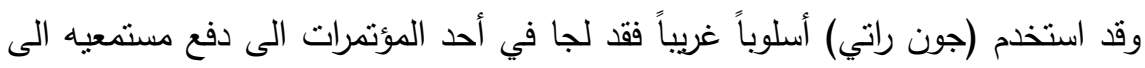

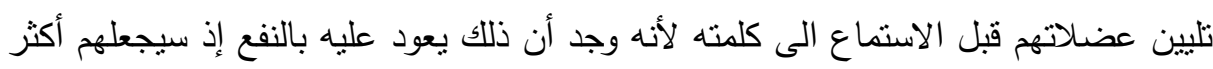

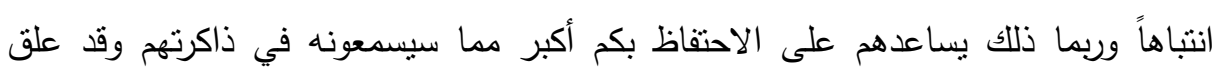


قائلاً: " لقد جهزت الجميع للاستماع "، فقد كانت هذه العبارات أو الطريقة مثالية لاستخدام اجسامهم لتطوير عقولهم.

وكانت أول اثشارة للعلاقة بين اللياقة البدنية وأداء المهام المعرفية البسيطة في دراسات أجريت في الستينات بالقرن الماضي، وقد أجرى هذه الدراسة في حقبة التسعينات عالم الجينات في معهد سوللك في كاليفورنيا على الفئران، وقد توصل الى أن التمرينات الرياضية تحفز نمو الخلايا العصبية لدى الفئران اذ يعتمد الدماغ وهو أثند أعضاء الجسم احتباجاً للطاقة على امتداد ثابت من المغذيات والاوكسجين عبر شبكة معقدة من الثعيرات الدموية، ويمكن أن يحفز النشاط البدني تكون خطوط الامداد تلك وفي وسعه كذلك تسهيل عملية صيانتها . nين

وقد اكتشف (ماثيو بايز) وهو يعمل لدى جامعة للتكنولوجيا في أستراليا أن ارتفاع ضغط الدم لا سيما في الثرايين المركزية الكبيرة التي تغذي الدماغ يؤدي إلى تدني الاداء المعرفي وبما أن النشاط البدني المنتظم يؤدي إلى خفض الضغئ فئن فمن المفترض أن يحمي إمداد المغذيات في الدماغ من هذا الضغط المفرط، ويقلل من خطر الاصابة بمرض السونس السكري والسمنة وهي من المشاكل التي تؤدي الى تعطيل نظام الانسولين في الدماغ، والذي يعتقد أنه

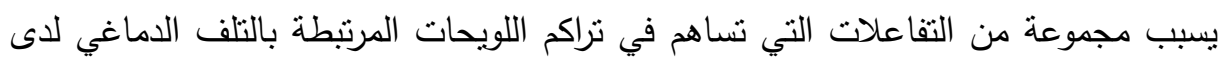

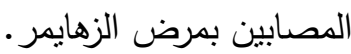

وأيضاً وجد أن التمارين الرياضية تحفز افراز النواقل العصبية منل : (السيروتونين

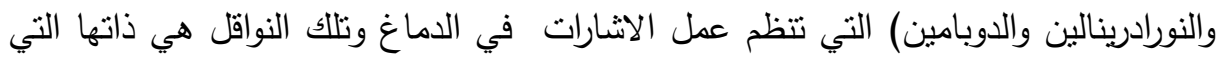
تعمل عليها العقاقير المضادة للاكتئاب والمعالجة لاضطراب قصور الانتباه وفرط الحركة، إذاً

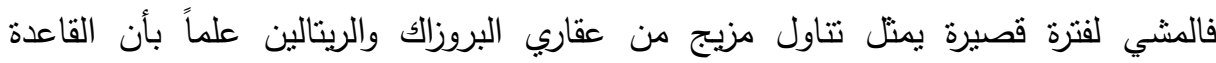

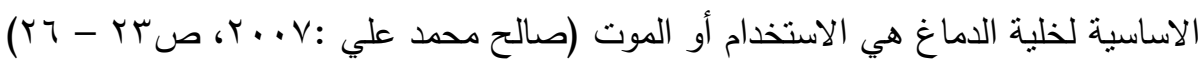
- أنثتت الكثير من التجارب و البحوث وجود علاقة ايجابية بين الذكاء وبين إحراز التقوق في استيعاب واتقان الاداء المهارى سواء كانت في الالعاب الرقمية مثل العاب الساحة 
والميدان أو كانت العاب فردية أو ثنائية مثل العاب المضرب أو العاب جماعية منل كرة القدم وكرة السلة والكرة الطائرة.

- نظهر أهمية الذكاء في الفعاليات الصعبة والمعقدة وتقل أهميته بشكل كبير في الفعاليات البسيطة والسهلة التي يكون فيها التماس والاحتكالك بالمناف ليس ذا أهمية كما في رفع

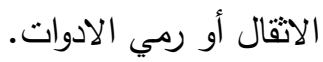
- هناك حركات لا تحتاج الى الذكاء بينما يؤدي الذكاء دوراً مهماً في حركات أخرى ضمن الادوات

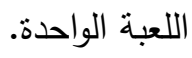
- ويمكننا أخيراً أن نؤكد على ضرورة ذكاء اللاعب لظروف اللعب في الوقت الحاضر ومدى التطور الحاصل في جميع مستويات الالعاب الرياضية المختلفة( نزار الطالب، وكامل

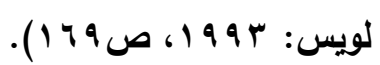
^- الأكاء الطبيعي: وهو قدرة الإنسان على التمييز بين الأشياء الحية (النباتات والحيوانات)،

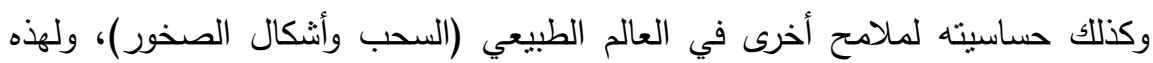
القدرة قيمتها وفائدتها في تاريخنا التطوري كصائدين، وجامعيين حاصدين، وزراعيين وهي

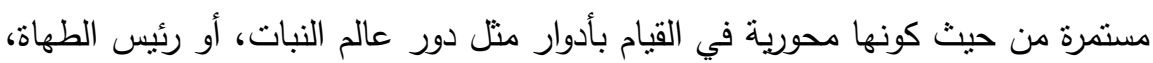
وأعنقد أن قدراً كبيراً من مجتمعنا الاستهلاكي يستمر ويستغل الذكاء الطبيعي والذبي يمكن أن يوجه ويوظف في التمييز بين السيارات وغيرها من السلع الاستهلاكية، وتقيد من هذاء الذكاء الطبيعي العلوم التي تتطلب التعرف على الأنماط والتمييز بينها(ثناء الضبع:

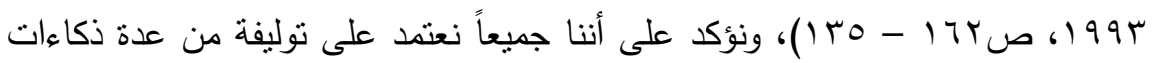
وقد يبدو أن علماء الرياضيات يعتمدون على الذكاء المنطقي الرياضي وحده غير أنه

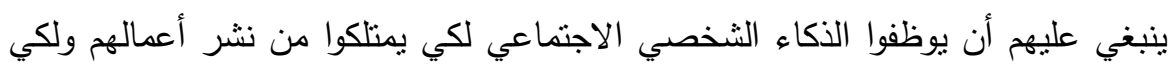
يتوافقوا مع متطلبات الجامعة. ويذهب جاردنر إلى أن الأسوياء من الناس قادرون على أن يفيدوا ويوظفوا جميع ذكاءاتهم ولكن الأفراد يتمايزون بالبروفيل الخاص بكل منهم أو صورتهم الذكائية فملامح هذاء مناء البروفيل هي نوليفة فريدة من ذكاءات ضعيفة نسبياً يستخدمونها لحل مشكلاتهم أو لتشكيل

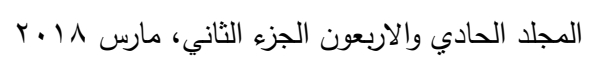


نواتج عملهم ونواحي القوة النسبية هذه ونواحي الضعف تساعد في تفسير الفروق الفردية

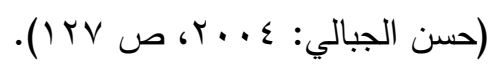

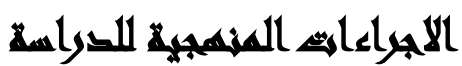

1 - نوع الدراسة: تتدرج هذه الدراسة ضمن نمط الدراسات الوصفية. r - المنهج المستخدم: تعتمد هذه الدراسة على المنهج الوصفي المقارن • ب - مدود الاراسة:

- حدود بشرية: عينة من مدرسة ثانوية في منطقة ريفية وأخري حضرية.

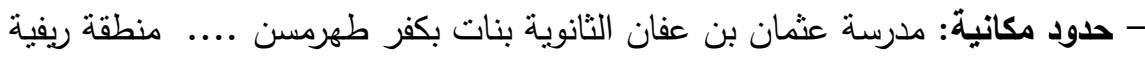
ومدرسة الثهيد نقيب إيهاب شتا الثانوية بنات بالهرم..... منطقة حضرية

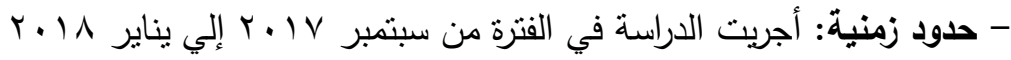
ع - أدوات الدراسة:

- مقياس المستوي الاجتماعي والاقتصادي والثقافي " من تصميم الباحثين"، وتكون من

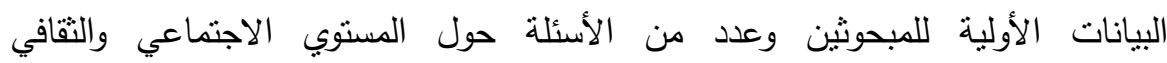
والاقتصادي للأسرة والدخل والعمل بالنسبة للأم والأب. - استبيان للتعرف علي الذكاءات المتعددة " من تصميم الباحثين، وكان من العناصر التالية

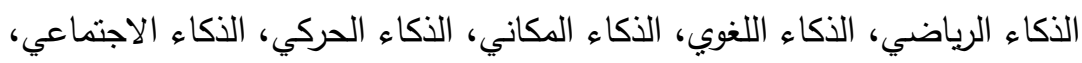
الذكاء الموسيقي، الذكاء الطبيعي، الذكاء الثخصي، وشمل كل عنصر عدد اء لاء سؤالا

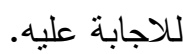
- مقياس التوافق البيئي " من تصميم الباحثة"، وتكون من البيانات الأولية للمبحوثين حول الاسم والسن والنوع والمكان الذي يعيش فيه وعدد من سؤال حول التوافق البيئي للمبحوثثين. ه- المقاييس الإحصائية المستخدمة في الاراسة: استخدم الباحثون في معالجة بيانات الدراسة بعض المقاييس الإحصائية والتي تتفق وطبيعة الدراسة ومتغيراتها المختلفة

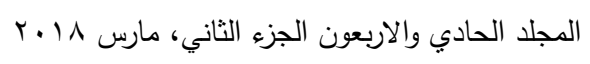


Statistical Package for وقد تم استخدام برنامج الحزمة الإحصائية للعلوم الاجتماعية Social Science (SPSS) باستخدام الأساليب الإحصائية التالية:

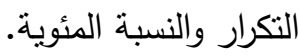
المتوسطات الحسابية والانحراف المعياري.

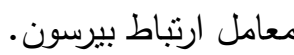
اختبار "ت" (T-test) لحساب الفروق بين منوسطات درجات المجموعات. تحليل التباين أحادي الاتجاه "ANOVA one way" لحساب الفروف بين مجموع مربعات متوسطات درجات المجموعات. اختبار أق فرق معنوي (LSD) لتحديد اتجاه الفروق بين استجابات أفراد عينة الدراسة إن

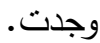

\section{تئائج الصواسمة}

جدول( ): دلالة الفرق بين منوسط درجات الريف والحضر في الذكاءات المتعددة (ن=. . بَ)

\begin{tabular}{|c|c|c|c|c|c|c|}
\hline مستوى الدلالة & قَِِمة ت & الانحرافت المعِياري & المنتوبط & العذد & مجموعة المقارنة & \\
\hline \multirow{2}{*}{ غخيز } & \multirow{2}{*}{$\cdot, 11 \mathrm{~V}$} & $\varepsilon, \Gamma \wedge$ & $r \cdot, \varepsilon$. & 10. & ريف & \multirow{2}{*}{ الذكاء اللغوب } \\
\hline & & $\varepsilon, 0 \varepsilon$ & $r \cdot, \varepsilon T$ & 10. & حضز & \\
\hline \multirow{2}{*}{ غيز } & \multirow{2}{*}{., 199} & $r, 7)$ & $r Y, \cdot q$ & 10. & ريف & \multirow{2}{*}{ الرياضكى } \\
\hline & & $r, T r$ & $r r, I V$ & 10. & حضز & \\
\hline \multirow{2}{*}{ غيز } & \multirow{2}{*}{$\cdot, \wedge \varepsilon \vee$} & $\varepsilon, 1 r$ & $r, Y \varepsilon$ & 10. & ريف & \multirow{2}{*}{ المكانتى } \\
\hline & & $\varepsilon, \varepsilon\}$ & $r 1,7 \pi$ & 10. & حضز & \\
\hline \multirow{2}{*}{ ديزي } & \multirow{2}{*}{$\cdot, r V$} & $\varepsilon, Y \wedge$ & $r \cdot, Y \varepsilon$ & 10. & ريف & \multirow{2}{*}{ الذكاء الحركى } \\
\hline & & $\varepsilon, r V$ & r., rO & 10. & حضز & \\
\hline \multirow{2}{*}{ عيز } & \multirow{2}{*}{$\cdot, T \vee \wedge$} & $r, \pi r$ & $r r, . q$ & 10. & ريف & \multirow{2}{*}{ الاجنَّاعى الأعاء } \\
\hline & & $r, v)$ & YY,YO & 10. & حضز & \\
\hline \multirow{2}{*}{ غيزل } & \multirow{2}{*}{$1, \ldots v$} & r,vo & $r, T \varepsilon$ & 10. & ريف & \multirow{2}{*}{ الشخصى الذكاء } \\
\hline & & $r, v \cdot$ & $r r_{,}, V$ & 10. & حضز & \\
\hline \multirow{2}{*}{ نغيز } & \multirow{2}{*}{ 1,人7T } & $\varepsilon$, YO & Y., YO & 10. & يف & \multirow{2}{*}{ الطيبعاء } \\
\hline & & $r, 09$ & $r, 1,$. & 10. & حضز & \\
\hline \multirow{2}{*}{ دآيزة } & \multirow{2}{*}{$\cdot, \lambda \cdot r$} & $\varepsilon, 1 \wedge$ & $Y, 0 V$ & 10. & ريف & \multirow{2}{*}{ الثموسيقَى الذئ } \\
\hline & & $r, \lambda \Lambda$ & 41,90 & 10. & حضز & \\
\hline \multirow{2}{*}{ غيزي } & \multirow{2}{*}{$., 1, T$} & YO,人T & 179, or & 10. & ريف & \multirow{2}{*}{ الجمالّى } \\
\hline & & $r 0, \cdot r$ & $(1), 91$ & 10. & حضز & \\
\hline
\end{tabular}

قيمة. ت الجدولية عند مستوى دلالةه ., • : 97 , 1

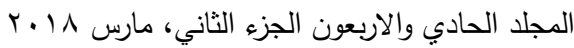


يتضح من بيانات الجدول السابق عدم وجود فروق دالة احصائياً بين الريف والحضر في

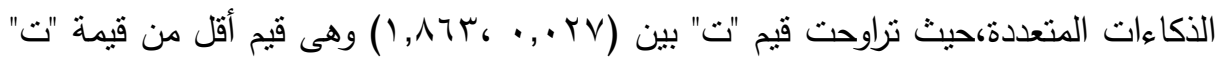

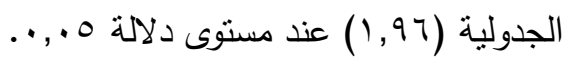

جدول(ץ): دلالة الفرق بين متوسط درجات الذكور والاناث في الذكاءات المتعددة

$$
\text { (ب) }
$$

\begin{tabular}{|c|c|c|c|c|c|c|}
\hline مستوي الالة & قيمة ت ت & الانحراف & المتوسط & العدد & مجموعة المقارنة & \\
\hline \multirow{2}{*}{ غير دالة } & \multirow{2}{*}{$1, \cdot r \wedge$} & 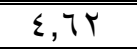 & $r \cdot, 1 \leq$ & 1147 & ذكور & \multirow{2}{*}{ الذكاء اللغوي } \\
\hline & & $\varepsilon, \Gamma$ & $T \cdot, T V$ & $17 \leq$ & اناث & \\
\hline \multirow{2}{*}{ غير دالة } & \multirow{2}{*}{$\cdot, \wedge \leq r$} & $r, 0 \leq$ & YI, $9 \leq$ & 117 & ذكور & \multirow{2}{*}{ الرياضي الزياء } \\
\hline & & $r, \Sigma)$ & YY,YA & 175 & اناث & \\
\hline \multirow{2}{*}{ غير دالة } & \multirow{2}{*}{$1, \leqslant 0 V$} & $r, 9 q$ & rI, גo & $1 \% 7$ & ذكور & \multirow{2}{*}{ الذكاء المكاني } \\
\hline & & $\varepsilon, 01$ & $r 1,1 r$ & $17 \varepsilon$ & اناث & \\
\hline \multirow{2}{*}{ غير دالة } & \multirow{2}{*}{$\cdot, r \cdot r$} & $\varepsilon, \varepsilon \Gamma$ & $r \cdot, r \cdot$ & 1147 & ذكور & \multirow{2}{*}{ الذكاء الحركي } \\
\hline & & $\varepsilon, 1 T$ & $r \cdot, r^{\prime}$ & $17 \leq$ & اناث & \\
\hline \multirow{2}{*}{ غير دالة } & \multirow{2}{*}{$\cdot, 994$} & $\Gamma, \wedge\rceil$ & YY, \&. & 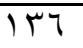 & ذكور & \multirow{2}{*}{ الإجتماءعي } \\
\hline & & $r, \leq q$ & Yl,A. & 175 & اناث & \\
\hline \multirow{2}{*}{ غير دالة } & \multirow{2}{*}{1,779} & $r, \vee \wedge$ & TY,YO & 1147 & ذكور & \multirow{2}{*}{ الثخصي } \\
\hline & & $r, 77$ & r1,0r & 175 & اناث & \\
\hline \multirow{2}{*}{ غير دالة } & \multirow{2}{*}{$\cdot, \leqslant \backslash 1$} & $r, v q$ & $r \cdot, O V$ & 1147 & ذكور & \multirow{2}{*}{ الطبيعي الذي } \\
\hline & & $\varepsilon, \cdot 9$ & $r \cdot, V T$ & $17 \varepsilon$ & اناث & \\
\hline \multirow{2}{*}{ غير دالة } & \multirow{2}{*}{ סחז, • } & $r, 09$ & Yl, 10 & 1T4 & ذكور & \multirow{2}{*}{ الذكوسيقي } \\
\hline & & $\varepsilon, \Gamma V$ & 41,79 & 175 & اناث & \\
\hline \multirow{2}{*}{ غير دالة } & \multirow{2}{*}{ • • } & $Y 0, \cdot V$ & $1 \vee 1, r q$ & 1147 & ذكور & \multirow{2}{*}{ الذرجةٍِ } \\
\hline & & ro, VV & $I V \cdot, r$ & $17 \varepsilon$ & اناث & \\
\hline
\end{tabular}

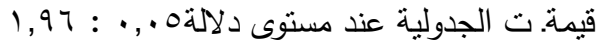

يتضح من بيانات الجدول السابق عدم وجود فروق دالة احصائياً بين الذكور والاناث

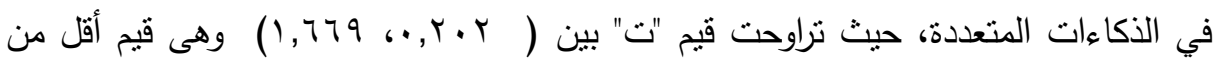

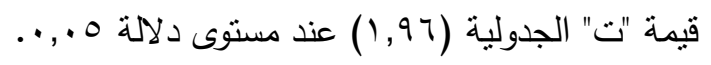


جدول(؟): الفرق بين متوسط درجات الذكاءات المتعددة تبعا للمستوي الاجتماعي والاقتصادي

\begin{tabular}{|c|c|c|c|c|c|c|}
\hline الالالة & قيمة ف & متوبط المربعات & الحرجة & المربعوع & مصدر التباين & البيان \\
\hline \multirow{3}{*}{ غير دالة } & \multirow{3}{*}{$r \varepsilon \cdot, \wedge 01$} & IArr,rVT & $r$ & พัฯ & بين المجموعات & \multirow{3}{*}{ اللغوي } \\
\hline & & $V, T, Y$ & rav & YYT.,VAO & داخل المجموعات & \\
\hline & & & rqq & oqrV,or. & المجموع & \\
\hline \multirow{3}{*}{ دالة عند } & \multirow{3}{*}{$1 \leq 1,194$} & $\wedge \vee \neg, 7) 0$ & $r$ & IVor, rq & بين المجموعات & \multirow{3}{*}{ الرياء } \\
\hline & & $7, Y \cdot 9$ & rqV & $1 \wedge \leqslant r, 90 V$ & داخل المجموعات & \\
\hline & & & $r 99$ & roqv, IAV & المجموع & \\
\hline \multirow{3}{*}{ دالة ع., بـ } & \multirow{3}{*}{$19 ., 09 \mathrm{~V}$} & $10 \leq 7, \wedge 91$ & $r$ & 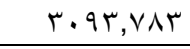 & بين المجموعات & \multirow{3}{*}{ الكاني } \\
\hline & & $\Lambda, 117$ & rav & $r \leq 1 \cdot, \leq \geq T V$ & داخل المجموعات & \\
\hline & & & rq9 & $00 . \leqslant, r_{0}$. & المجموع & \\
\hline \multirow{3}{*}{ غير دالة } & \multirow{3}{*}{$r \leqslant 1, V \pi r$} & $17 \wedge \varepsilon, 9 Y T$ & r & 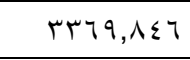 & بين المجموعات & \multirow{3}{*}{ الحركي } \\
\hline & & 7,979 & rqV & $r+79,9 \ldots$ & داخل المجموعات & \\
\hline & & & rq9 & $0 \leqslant r q, V \leqslant V$ & المجموع & \\
\hline \multirow{3}{*}{ الـ دالة عند } & \multirow{3}{*}{ rฯA, IAV } & $1 r \wedge q, v \cdot r$ & $r$ & rova, \&.० & بين المجموعات & \multirow{3}{*}{ الاجتماء } \\
\hline & & $\varepsilon, \wedge \cdot 9$ & rav & $1 \leq r \wedge, r \neg r$ & داخل المجموعات & \\
\hline & & & r१q & $\varepsilon \cdots v, 7 \uparrow \vee$ & المجموع & \\
\hline \multirow{3}{*}{ غير دالة } & \multirow{3}{*}{$r \varepsilon \cdot, \wedge r$} & $\mid$ |rAr,VYI & $r$ & roTV, $\leqslant \leqslant Y$ & بين المجموعات & \multirow{3}{*}{ الثذي الذاء } \\
\hline & & $0, r \leqslant 0$ & rqV & $101 \mathrm{~V}, \mathrm{r} 90$ & داخل المجموعات & \\
\hline & & & rqq & $\varepsilon 10 \leqslant, A r V$ & المجموع & \\
\hline \multirow{3}{*}{ دالة عند } & \multirow{3}{*}{$1 \vee q, r \cdot q$} & IrVV,TVO & $r$ & rooo,ro. & بين المجموعات & \multirow{3}{*}{ الطبيع } \\
\hline & & $V, 1 Y 7$ & rqV & $Y \| T, r \wedge V$ & داخل المجموعات & \\
\hline & & & rq9 & 纟TV1,7rV & المجموع & \\
\hline \multirow{3}{*}{ 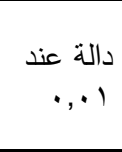 } & \multirow{3}{*}{$r \varepsilon \cdot, \vee \wedge \uparrow$} & $10 \ldots, v \wedge r$ & $r$ & $r . .1,07 \mathrm{~V}$ & بين المجموعات & \multirow{3}{*}{ الموسي } \\
\hline & & TH T T & rqV & 1101,104 & داخل المجموعات & \\
\hline & & & rqq & EAOY,VY. & المجموع & \\
\hline \multirow{3}{*}{ دالة عند } & \multirow{3}{*}{$\begin{array}{r}\text { ITOY,A } \\
\wedge\end{array}$} & $A V \cdot r r, Y T T$ & $r$ & $\mid V \leq . \leq 7,041$ & بين المجموعات & \multirow{3}{*}{ الدرجة } \\
\hline & & $T \Sigma$, TYT & r9V & $191 \cdot\{, 117$ & داخل المجموعات & \\
\hline & & & rqq & $194101, r \leqslant V$ & المجموع & \\
\hline
\end{tabular}

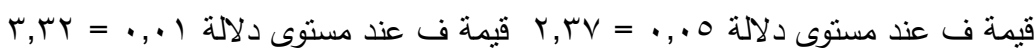

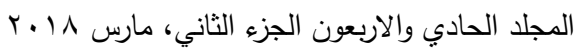


ويتضح من بيانات الجدول السابق عدم وجود فروق ذات دلالة إحصائية بين منوسط درجات الذكاءات المتعددة تبعا لمستوي الاجتماعي والاقتصادي والثقافي حيث تراوحت قيم

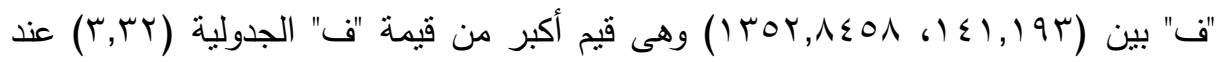
مستوى دلالة ا.,... جدول(§): دلالة الفرق بين الفرق بين منوسط درجات الذكاءات المتعددة تبعا للتوافق البيئي $(r+\cdots)$

\begin{tabular}{|c|c|c|c|c|c|c|}
\hline مستوى & قيمة ت & الانحراف & المتوسط & العدد الع & مجموعة المقارنة & \\
\hline \multirow{2}{*}{ غير دالة } & \multirow{2}{*}{$1, \leqslant 17$} & $\varepsilon, 0 r$ & $r \cdot, V V$ & 174 & اتجاه & \multirow[t]{2}{*}{ الذكاء اللغوي } \\
\hline & & $\varepsilon, \Gamma \varepsilon$ & $r \cdot, \cdot \varepsilon$ & $1{ }^{1}$ & دافعية & \\
\hline \multirow{2}{*}{ غير دالة } & \multirow{2}{*}{$\cdot, \wedge \circ r$} & $r, r q$ & Y1,9V & $17 r$ & اتجاه & \multirow[t]{2}{*}{ الذكاء الرياضي } \\
\hline & & $r, 07$ & rY,rו & $1 \% 1$ & دافعية & \\
\hline \multirow{2}{*}{ غير دالة } & \multirow{2}{*}{$\cdot, \varepsilon \wedge \wedge$} & $\varepsilon, \cdot 1$ & Y1,07 & $17 r$ & اتجاه & \multirow[t]{2}{*}{ الذكاء المكاني } \\
\hline & & $\varepsilon, 71$ & rl,rr & $1 \Gamma \Lambda$ & دافعية & \\
\hline \multirow{2}{*}{ غير دالة } & \multirow{2}{*}{$1, V \vee r$} & $\varepsilon, 1$. & $r \cdot, 70$ & 174 & اتجاه & \multirow{2}{*}{ الذكاء الحركي } \\
\hline & & $\varepsilon, \Sigma 1$ & $19, \vee \wedge$ & $1 \mu \lambda$ & دافعية & \\
\hline \multirow{2}{*}{ غير دالة } & \multirow{2}{*}{., 19.} & $r, \tau$. & $r r_{,}, r$. & $17 r$ & اتجاه & \multirow{2}{*}{ الذكاء الاجتماعي } \\
\hline & & $r, v \varepsilon$ & $r Y, I r$ & 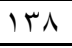 & دافعية & \\
\hline \multirow{2}{*}{ غير دالة } & \multirow{2}{*}{$\cdot, 0 . r$} & $r, 1 r$ & $r 1,97$ & $17 r$ & اتجاه & \multirow[t]{2}{*}{ الذكاء الشخصي } \\
\hline & & $\varepsilon, \pi$ & YI,V $v$ & $1 \mathrm{~N}$ & دافعية & \\
\hline \multirow{2}{*}{ دالة عند } & \multirow{2}{*}{$r, r) \varepsilon$} & 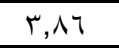 & 41,17 & $17 r$ & اتجاه & \multirow[t]{2}{*}{ الذكاء الطبيعي } \\
\hline & & $r, 99$ & $r \cdot, 11$ & 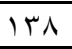 & دافعية & \\
\hline \multirow{2}{*}{ غير دالة } & \multirow{2}{*}{$\cdot, \wedge r$} & $r, 97$ & YI,VA & $17 r$ & اتجاه & \multirow[t]{2}{*}{ الذكاء الموسيقي } \\
\hline & & $\varepsilon, 1 T$ & $r,, V \leq$ & 151 & دافعية & \\
\hline \multirow{2}{*}{ غير دالة } & \multirow{2}{*}{$\cdot, 9 \wedge r$} & $r \leqslant, 97$ & $I V T, \cdot \varepsilon$ & 174 & اتجاه & \multirow[t]{2}{*}{ اجمالي الدرجة } \\
\hline & & $r 0,90$ & 179,10 & $1 \mathrm{MN}$ & دافعية & \\
\hline
\end{tabular}

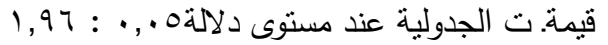

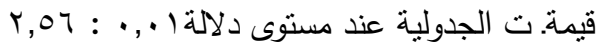


يتضح من بيانات الجدول السابق عدم وجود فروق دالة احصائياً متوسط درجات

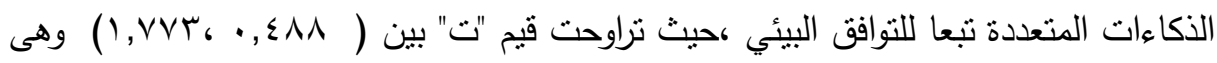

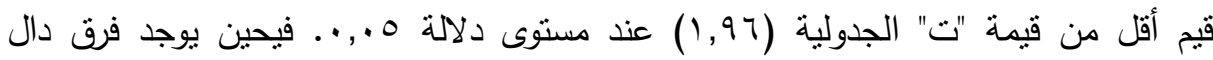
احصائياً في الذكاء الطبيعي عند مستوى دلالة ا. ., . لصالح الاتجاه.

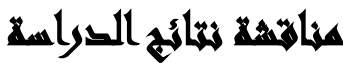

أولا: خصائص عينة الدراسة:

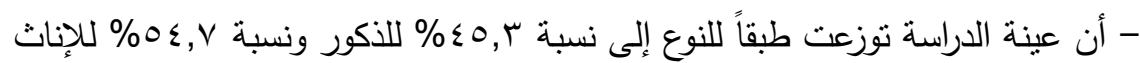

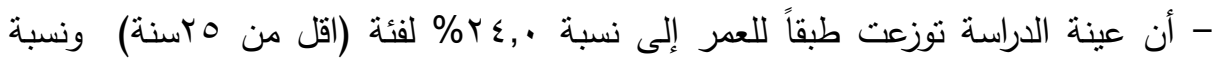

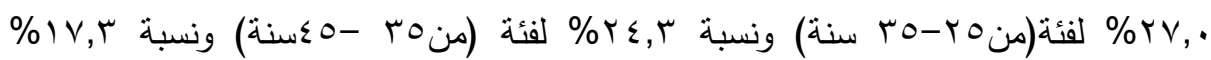

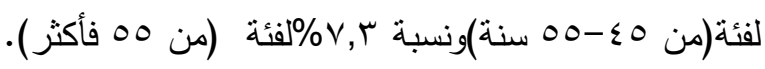
- أن عينة الدراسة توزعت طبقاً للمؤهل إلى نسبة >,؛ إ للمؤهل اقل من المتوسط، ونسبة

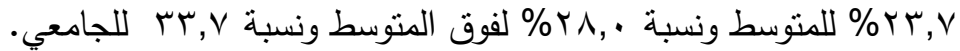

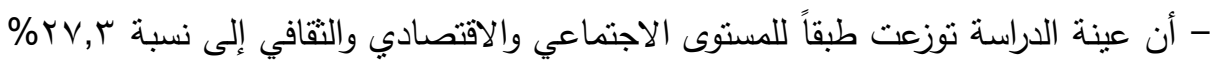

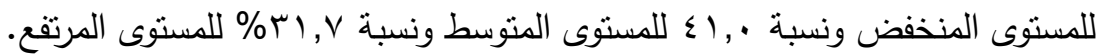

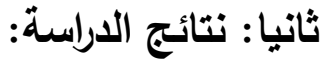
الفرض الأول: توجد فروق ذات دلالة إحصائية بين متوسطات الذكاءات المتعددة في الريف والحضر. تم استخدام اختبار "ت" للمجموعات المستقلة للتفرقة بين الريف والحضر، واتضح من البيانات عدم وجود فروق دالة احصائياً بين الريف والحضر في الذكاءات المتعددة،حيث

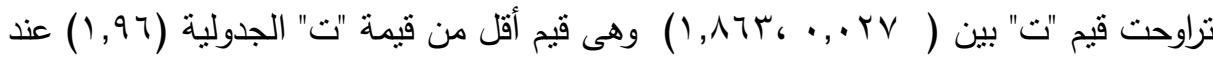


وتتفق نتائج هذا الفرض في بعض منها مع دراسة: موفق سليم صبح بشارة، أثز

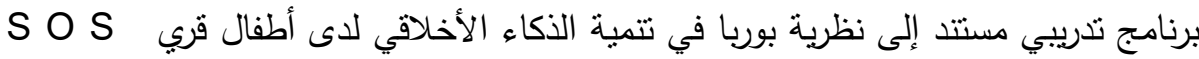

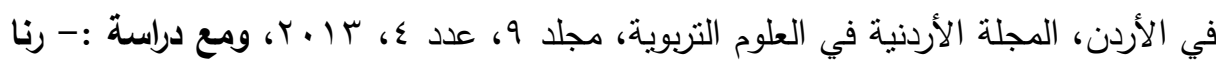
قوشحة دراسة الفرد في الذكاء المتعدد بين طلاب بعض الكليات النظرية والعملية، رسالة

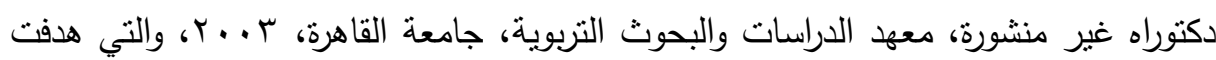
إلى دراسة الفروق بين الكليات العملية والنظرية في الذكاء المتعدد وفق متغيرات السنة الدراسية والجنس على عينة من . . 7 طالباً وطالبة استخدمت فيها مقياس ميداني توصلت إلى نتائج الفروق وهي لا فروق دالة بين طلبة الكليات العملي والنظري حسب متغيري السنة الدراسية والنوع بالذكاء الموسيقي رغم اختلاف ترتيب الذكاء بينما كانت الفروق لصالح الكليات العملية في الذكاء الحركي والمكاني واللغوي والاجتماعي والثخصي. الفرض الثاني: توجد فروق ذات دلالة احصائية بين درجات متوسطات الأكاعات المتعددة

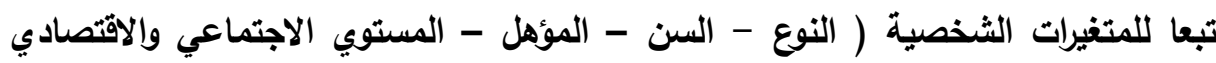
والثقافي).

- توجد فروق ذات دلالة احصائية بين درجات متوسطات الأكاءات المتعددة تبعا للنوع

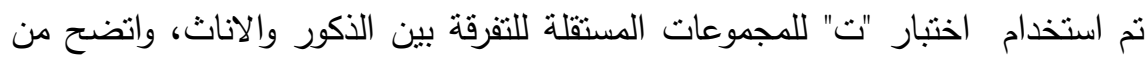

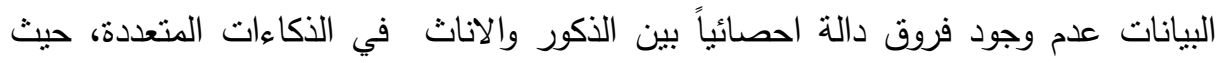

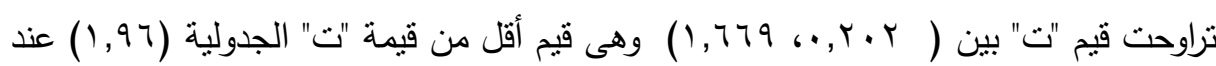

$$
\text { مستوى دلالة ه.,.. }
$$

- توجد فروق ذات دلالة احصائية بين درجات متوسطات الذكاءات المتعددة تبعا للسن تم استخدام تحليل التباين الاحادي ANOVA ، يتضح من البيانات عدم وجود فروق

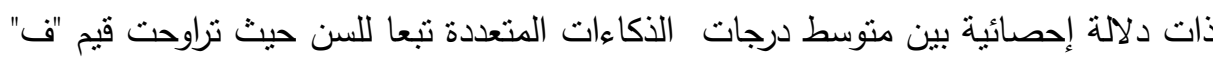

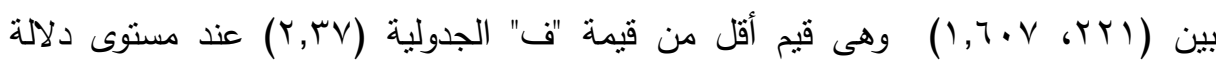
., .0 
- توجد فروق ذات دلالة احصائية بين درجات متوسطات الأكاءات المتعددة تبعا للمؤهل

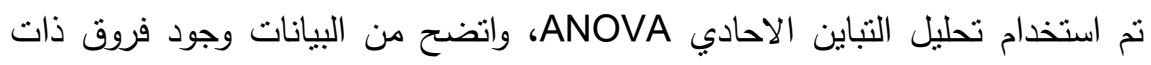

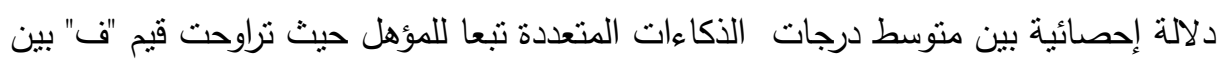

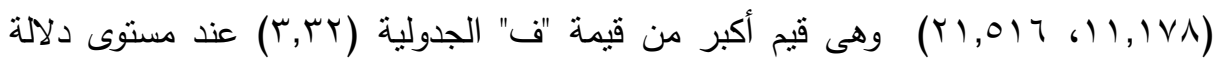
ا .... . ولمعرفة اي من المجموعات (المؤهلات) سبب الاختلاف نم استخدام اختبار اقل فرق

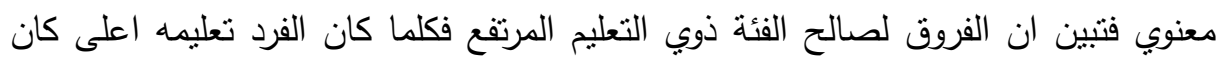
ذكائه اعلى. - توجد فروق ذات دلالة احصائية بين درجات متوسطات الذكاءات المتعددة تبعا المستوي الاجتماعي والاقتصادي والثثافي

تم استخدام تحليل التباين الاحادي ANOVA، واتضح من بيانات الجدول السابق عدم وجود فروق ذات دلالة إحصائية بين متوسط درجات الذكاءات المتعددة تبعا لمستوي

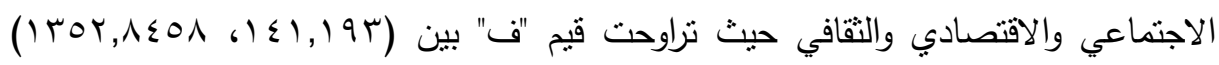

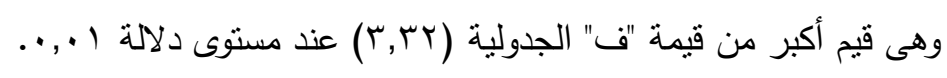

وتتفق نتائج هذا الفرض في بعض منها مع الدراسات التالية زهوة منير السيد حجاج،

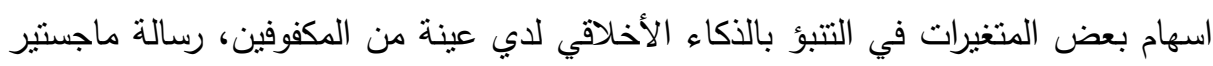

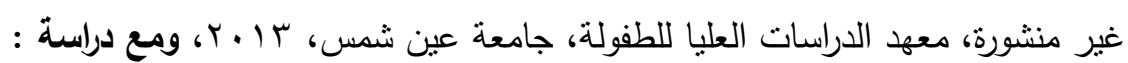
Kindlon and Thompson 2009 Raising Can Protecting the Moral Life of Children, New York, Ballantine .

والتي هدفت إلي الكثف عن العلاقة الارتباطية بين الذكاء الأخلافي ومستويات الذكاء

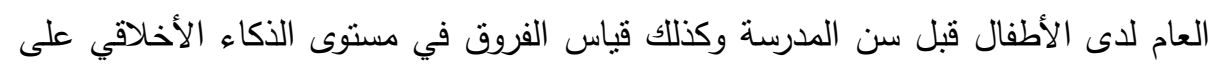
وفق متغير النوع ذكور - إناث.

الفرض الثالث: توجد فروق ذات دلالة احصائية بين درجات المجموعتين في الاكاءات المتعددة تبعا للتوافق البيئي ( الدافعية - الاتجاه ) . 
تم استخدام اختبار "ت" للمجموعات المستقلة للتفرقة بين الريف والحضر، واتضح من البيانات عدم وجود فروق دالة احصائياً منوسط درجات الذكاءات المتعددة تبعا للتوافق البيئي

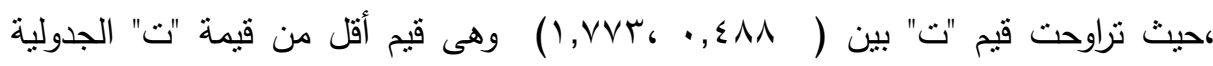

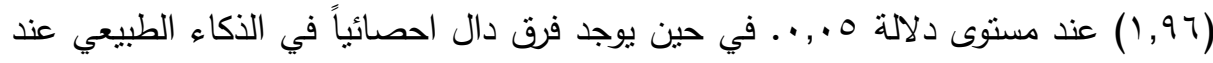
مستوى دلالة ا. ., •. لصالح الاتجاه. - عدم وجود فروق دالة احصائياً بين الذكور والاناث في الذكاءات المتعددة، حيث نراوحت

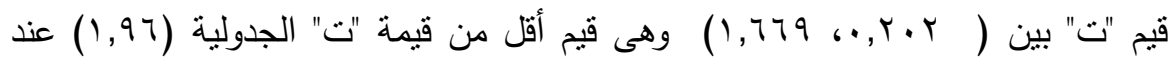
مستوى دلالة 0 ., •..

- عدم وجود فروق ذات دلالة إحصائية بين منوسط درجات الذكاءات المتعددة تبعا للسن

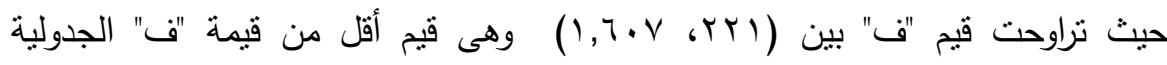

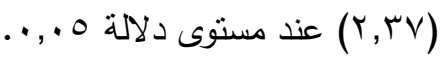
- وجود فروق ذات دلالة إحصائية بين متوسط درجات الذكاءات المتعددة تبعا للمؤهل حيث

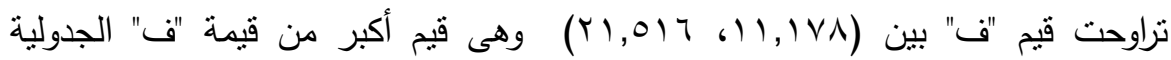

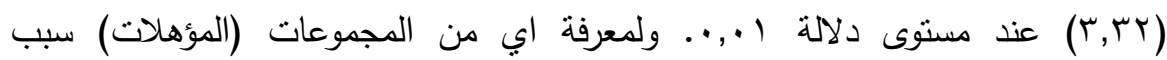
الاختلاف تم استخدام اختبار اقل فرق معنوي فنتبين ان الفروق لصالح الفئة ذوي التعليم المرتفع فكلما كان الفرد تعليمه اعلى كان ذكائه اعلى. - عدم وجود فروق ذات دلالة إحصائية بين متوسط درجات الذكاءات المتعددة تبعا

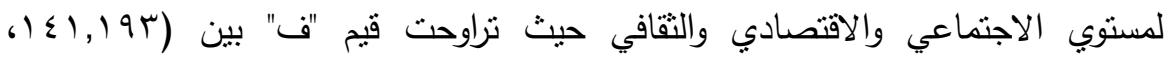

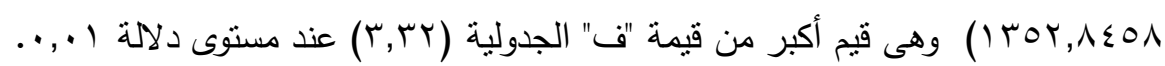

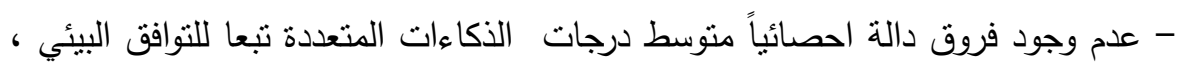

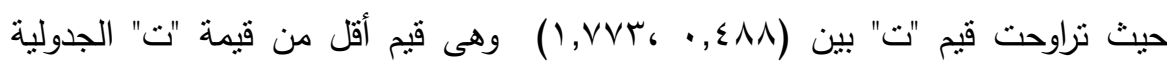

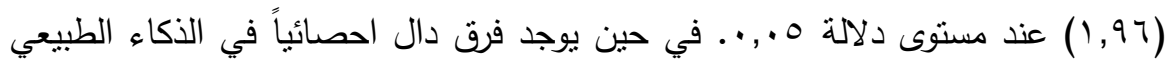
عند مستوى دلالة ا +., • لصالح الاتجاه. 
Costa and ) وتتفق نتائج هذا الفرض في بعض منها مع دراسة:- كوستا وكاليك

Costa, A. Kallicks, B. (2017). Habit - of - Mind. Retrieved, 23-7-2017, from http://www.docstoc.com/docs/15189296/Habits-of-mind

أن العادة العقلية تتكون من عدد من المهارات والاتجاهات والقيم والخبرات السابقة

والميول، ومع دراسة عبد العظيم المصدر ^ . . ب الذكاء الانفعالي وعلاقته ببعض المتغيرات

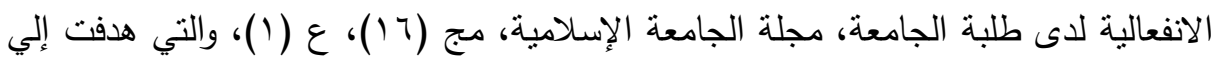

دراسة العلاقة بين الذكاء العاطفي ومجموعة من المتغيرات العاطفية تمثلت في وجهة الضبط الضط

وتقدير الذات والخجل، ومع دراسة:- فرنهام ويتريدز (Furnham \& Petrides, 2006) Trait Emotional Intelligence and Happiness Social behavior and Personalist, Vol.31, 8, pp. 815- 824

والتي هدفت إلى التعرف على العلاقة بين الذكاء العاطفي والسعادة والانبساط والانفتاح

والعصبية، وشملت الدراسة عينة مكونة من ^^ فرداً، وتوصلت إلى أن الذكاء العاطفي يرتبط

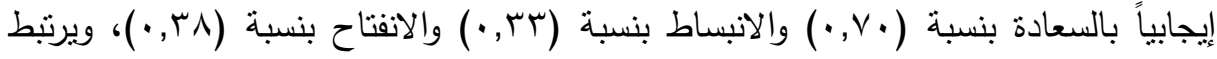

$$
\begin{aligned}
& \text { عكسياً بالعصبية بنسبة تبلغ (-. •. • • •). } \\
& \text { ثالثا: توصيات الدراسة: }
\end{aligned}
$$

- العمل على زيادة ثقة الفرد بنفسه وتكوين مفهوم ذات إيجابي لديه. - اعادة النظر فى دراسة أساليب التعلم النشط وأساليب التعامل مع الاطفال وبخاصة من دئه لديهم مشاكل مع النوافق البيئي في بيئتهم الاجتماعية والتعليمية. - تزويد القائمين بالإثراف والتوجيه بالوسائل وأدوات القياس العلمية السليمة لنقويم أداء هؤلاء الأطفال فيما يتعلق بأنواع الذكاءات المتعددة. 


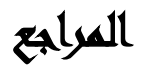

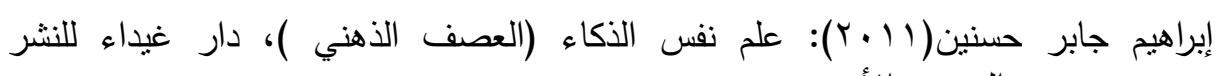
والتوزيع، الأردن

أحمد شفيق السكرى( . . ب): قاموس الخدمة الاجتماعية والخدمات الاجتماعية، دار المعرفة

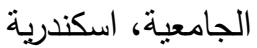

أمينه الألفي(ع ( †): مناهج رياض الأطفال، مكتبة الرشد، المملكة العربية السعودية

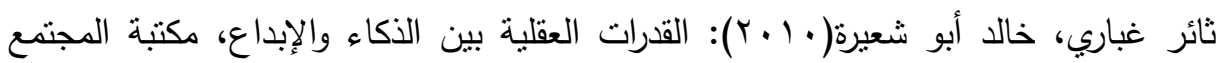

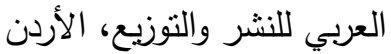

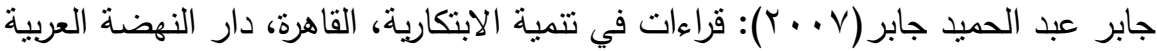

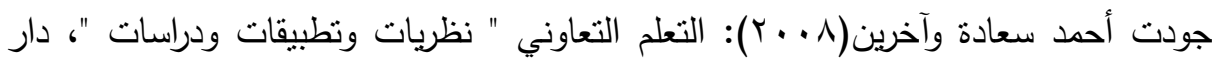

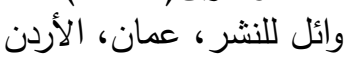

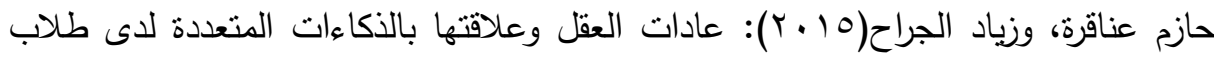
السنة التحضيرية بجامعة طيية في المملكة العربية السعودية، مجلة المنارة،

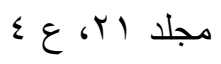

حسن ابراهيم عبد العال (^ . . ץ): التربية الابداعية ضرورة وجودية، عمان، دار الفكر

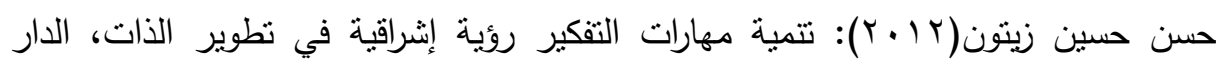
الصوتية للتربية، السعودية التية الترات

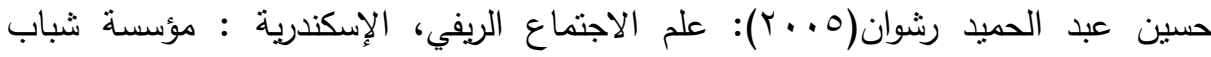
الجامعة الجمُ

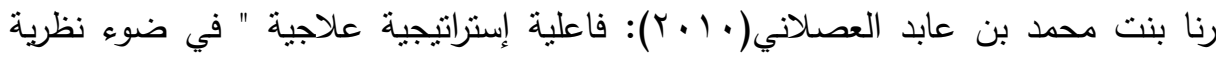

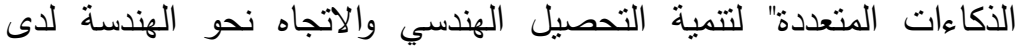

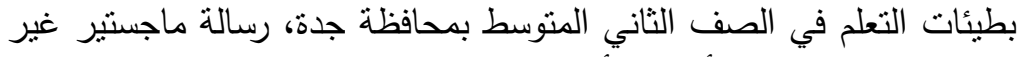

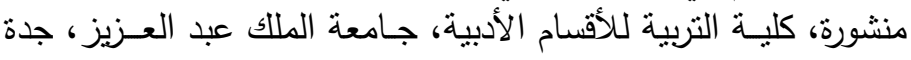

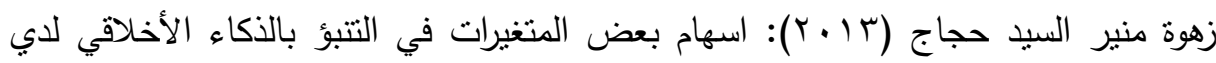

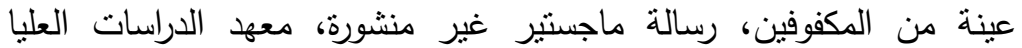

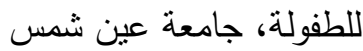

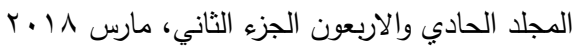


عبد القادر محمد(9 . . ץ): نظريات التعلم والتعليم، مكتبة النهضة المصرية، القاهرة . محمد عاطف غيث(999 (1)): دراسات فى علم الاجتماع القروى، الإسكندرية : دار المعارف.

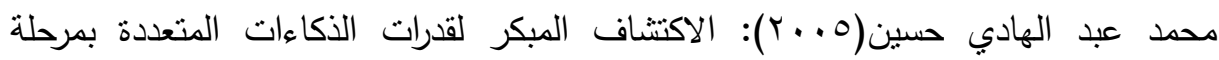
الطفولة المبكرة، دار الفكر ، الأردن.

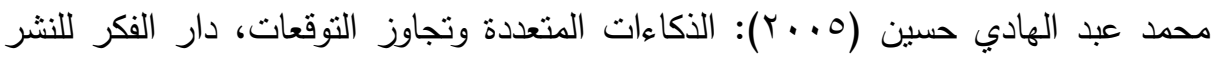
والتوزيع، القاهرة.

محمود داود الربيعي، وآخرون(r ( †): نظريات التعلم والعمليات العقلية، لبنان، دار الكتب العلمية.

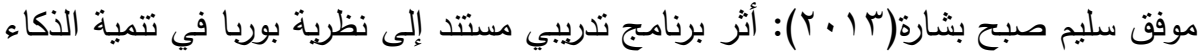

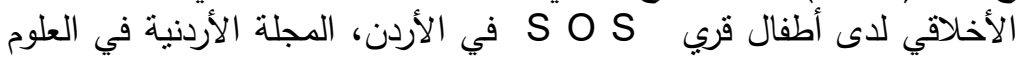

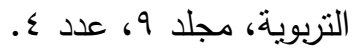

يحي حسن درويش(ع + †): معجم مصطلحات الخدمة الاجتماعية ( إنجليزي - عربي )، القاهرة : الثركة المصرية العالمية للنشر لونجمان.

Checkley, Kathey (1997); The first seren and the eighth : a conversation with hawardner, Edvcation leader ship, V . 55 , No . BEDI 970222/2.

Costa, A. Kallicks, B. (2017); Habit - of - Mind. Retrieved, 23-7-2017, from http://www.docstoc.com/docs/15189296/Habits-of-mind.

Gardner, H. (1991); Frames of Mind : The Theory of Multiple Intelligences . New York : Basic Books, Inc

Gardner, Howard (1991); The unschooled mind: How children think and how schools should teach, New York .

Mayer, j. \& Salovey, P. (2014); What is emotional intelligence? In P. Salovey \& D. Sluyter (Eds.). Emotional development and emotional intelligence: Implications for Educators. New York: Basic Books.

$$
\text { المجلد الحادي والاربعون الجزء الثاني، مارس ^1 ــ }
$$




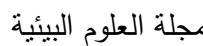

معهذ الدراسات والبحوث البيئية - جامعة عين شمس البئ

\title{
MULTIPLE INTELLIGENCE AND ITS RELATION TO THE INDIVIDUAL VARIATION IN THE CONTEXT OF ENVIRONMENTAL HARMONY COMPARATIVE STUDY BETWEEN URBAN AND RURAL
}

\author{
Ebrahem, R. S. ${ }^{(1)}$; Safwat, A. S..$^{(2)}$; El-dahan, , H. ${ }^{(3)}$ \\ and Abd-Elghany Asmma, I.
}

1) Faculty of Art, Ain Shams University 2) Faculty of Art, Siwes Canal University 3) Faculty of Education Quality, Ain Shams University

\begin{abstract}
The study aimed to detect the relationship between multiple intelligences and their relation to personal variables and environmental compatibility, and to reveal the relationship between multiple intelligences and their relation to personal variables and environmental compatibility by applying to a rural and other urban sample. This study falls within the pattern of analytical descriptive studies using the analytical descriptive method and the comparative method, Socioeconomic scale and cultural scale, and a measure of multiple intelligences, "and the scale of environmental compatibility, and applied the study at the school of Othman bin Affan secondary girls in Kafr Tuhrmsen .. rural area, the school of martyr Captain Ihab Sheta The study concluded that there were no statistically significant differences between males and females in multiple intelligences, and there were no statistically significant differences between the mean scores of multiple intelligences according to age, depending on the qualification., And the absence of differences statistically significant average degrees of multiple intelligences according to environmental compatibility, and recommended the study of the need to work to increase the confidence of the individual himself and the formation of a positive concept has, and reconsider the study of active learning

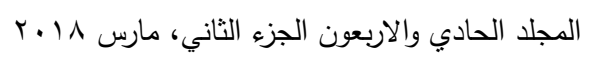




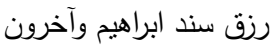

methods and methods of dealing with young people, especially those with problems with environmental compatibility in the environment They are social and educational.

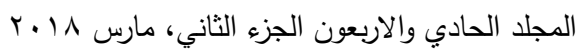

